\title{
LLNL Site Plan for a MOX Fuel Lead Assembly Mission in Support of Surplus Plutonium Disposition
}

\author{
Mark C. Bronson
}

October 1, 1997

This is an informal report intended primarily for internal or limited external distribution. The opinions and conclusions stated are those of the author and may or may not be those of the Laboratory.

Work performed under the auspices of the U.S. Department of Energy by the Lawrence Livermore National Laboratory under Contract W-7405-Eng-48. 


\section{DISCLAIMER}

This document was prepared as an account of work sponsored by an agency of the United States Government. Neither the United States Government nor the University of California nor any of their employees, makes any warranty, express or implied, or assumes any legal liability or responsibility for the accuracy, completeness, or usefulness of any information, apparatus, product, or process disclosed, or represents that its use would not infringe privately owned rights. Reference herein to any specific commercial product, process, or service by trade name, trademark, manufacturer, or otherwise, does not necessarily constitute or imply its endorsement, recommendation, or favoring by the United States Government or the University of California. The views and opinions of authors expressed herein do not necessarily state or reflect those of the United States Government or the University of California, and shall not be used for advertising or product endorsement purposes.

This report has been reproduced directly from the best available copy.

Available to DOE and DOE contractors from the Office of Scientific and Technical Information

P.O. Box 62, Oak Ridge, TN 37831

Prices available from (615) 576-8401, FTS 626-8401

Available to the public from the

National Technical Information Service

U.S. Department of Commerce

5285 Port Royal Rd.,

Springfield, VA 22161 


\section{LLNL Site Plan for a MOX Fuel Lead Assembly Mission in Support of Surplus Plutonium Disposition}

October 1997

LAWRENCE LIVERMORE NATIONAL LABORATORY UNIVERSITY OF CALIFORNIA • LIVERMORE • CALIFORNIA 94550 


\section{CONTENTS}

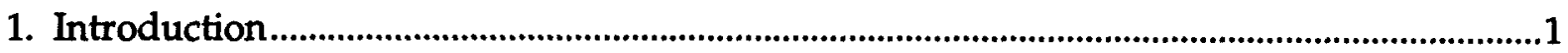

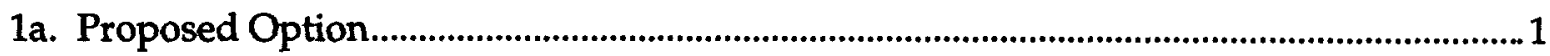

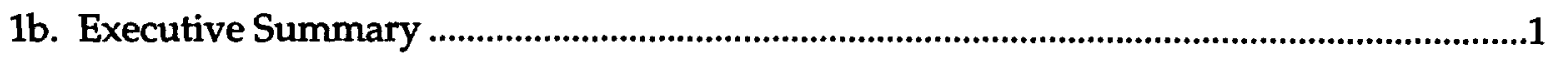

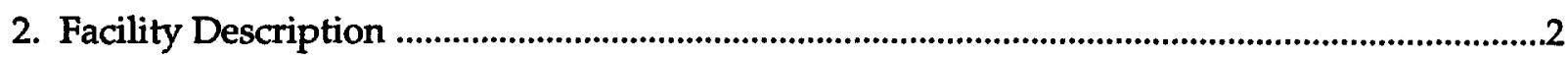

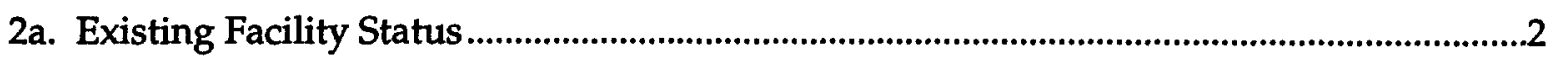

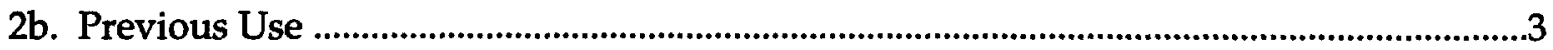

2c. Advantages for MOX Fabrication Utilization...............................................................4

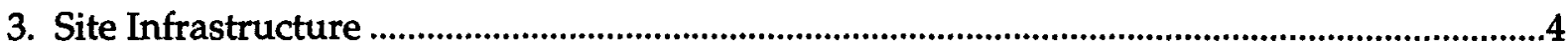

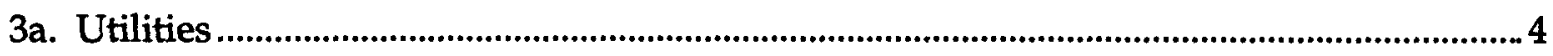

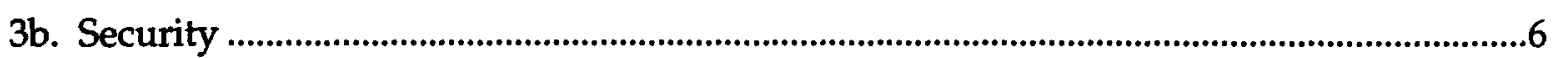

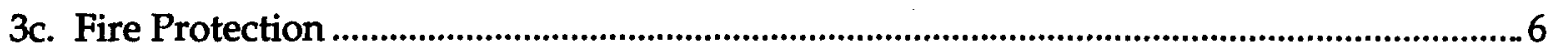

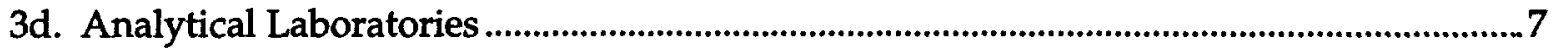

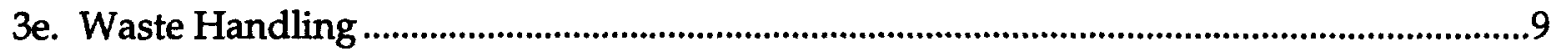

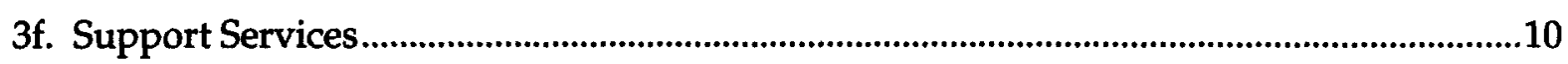

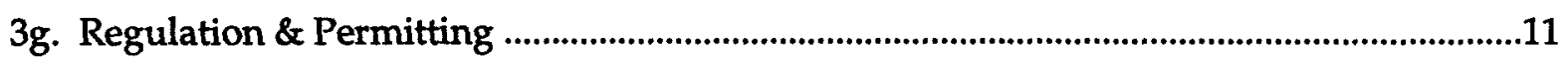

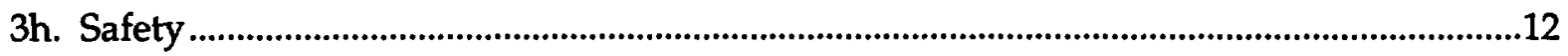

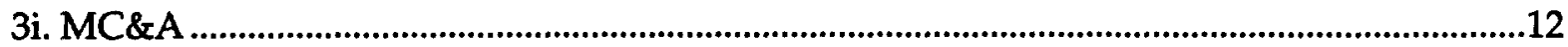

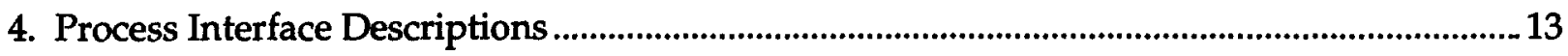

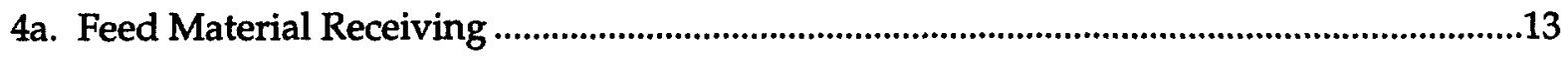

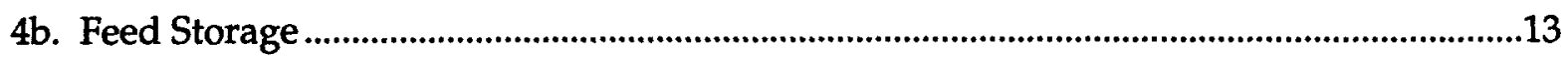

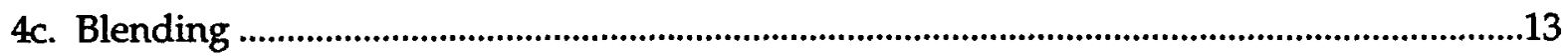

4d. Pellet Production \& Inspection ...........................................................................................15

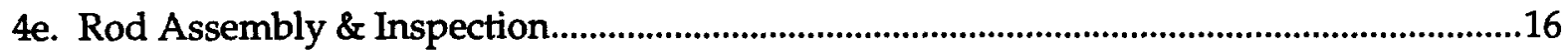

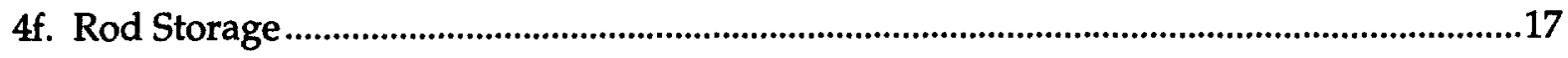

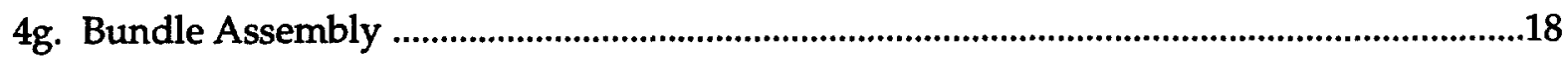

4h. Bundle Storage.......................................................................................................................18

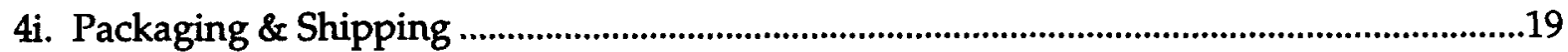

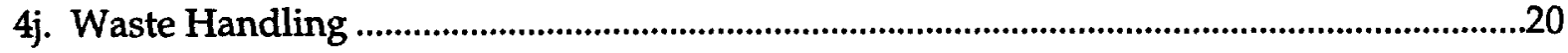

5. Proposed Facility Modifications......................................................................................................20

5a. Modification Required To Install MOX Fuel Fabrication Equipment ..............................20

5b. Modification Required To Accomplish DOE Order Compliance ......................................22

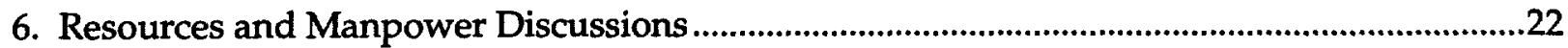

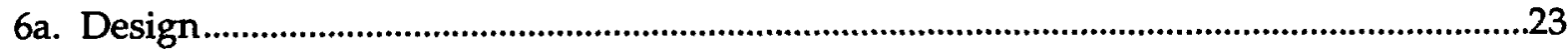




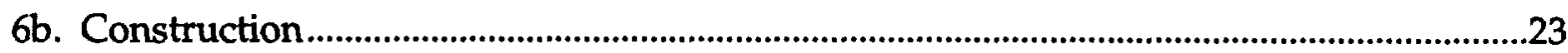

6c. Operation

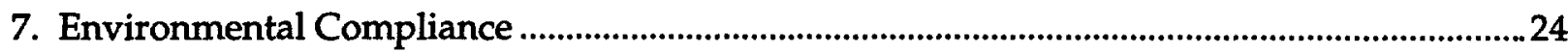

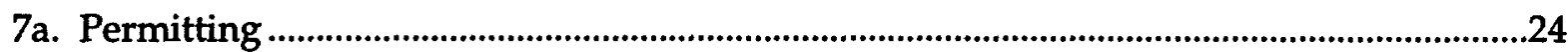

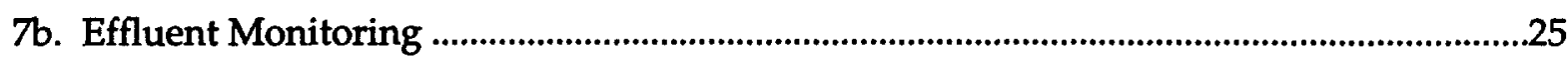

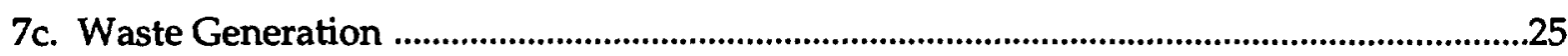

8. Cost \& Schedule-Not applicable

9. Variance from Baseline Discussion-Not applicable

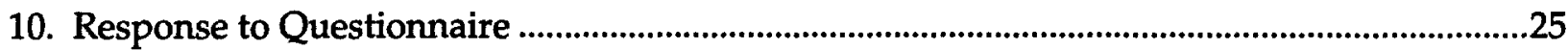

11. Cost and Schedule Risk-Not applicable

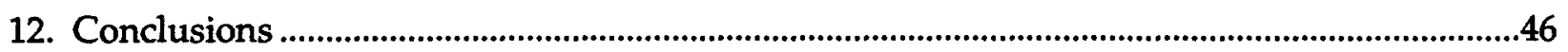

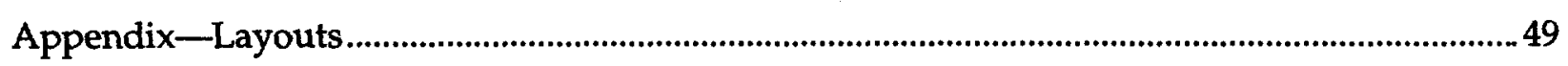




\section{LLNL SITE PLAN FOR A MOX FUEL LEAD ASSEMBLY MISSION IN SUPPORT OF SURPLUS PLUTONIUM DISPOSITION}

\section{Introduction}

\section{1a. Proposed Option}

Lawrence Livermore National Laboratory (LLNL) has only one proposed option for a MOX Lead Assembly Mission in support of Surplus Plutonium Disposition. This document will describe the option that is being proposed for the LLNL site.

\section{1b. Executive Summary}

The principal facilities that LLNL would use to support a MOX Fuel Lead Assembly Mission are Building 332 and Building 334. Both of these buildings are within the security boundary known as the LLNL Superblock. Building 332 is the LLNL Plutonium Facility. As an operational plutonium facility, it has all the infrastructure and support services required for plutonium operations.

The LLNL Plutonium Facility routinely handles kilogram quantities of plutonium and uranium. Currently, the building is limited to a plutonium inventory of 700 kilograms and a uranium inventory of 300 kilograms. Process rooms (excluding the vaults) are limited to an inventory of 20 kilograms per room. Ongoing operations include: receiving SSTs, material receipt, storage, metal machining and casting, welding, metal-to-oxide conversion, purification, molten salt operations, chlorination, oxide calcination, cold pressing and sintering, vitrification, encapsulation, chemical analysis, metallography and microprobe analysis, waste material processing, material accountability measurements, packaging, and material shipping.

Building 334 is the Hardened Engineering Test Building. This building supports environmental and radiation measurements on encapsulated plutonium and uranium components. Other existing facilities that would be used to support a MOX Fuel Lead Assembly Mission include Building 335 for hardware receiving and storage and TRU and LLW waste storage and shipping facilities, and Building 331 or Building 241 for storage of depleted uranium.

An overview of how the MOX Fuel Lead Assembly Mission would be accomplished at LLNL is as follows. Plutonium oxide would be received at the LLNL Plutonium Facility via SST. The SST would be unloaded and the shipping containers transported into the Plutonium Facility and placed into temporary storage. The shipping containers would then be unloaded, and the 
plutonium oxide containers would be measured for plutonium content by nondestructive assay techniques. The plutonium oxide containers would be placed into one of the Plutonium Facility storage vaults until needed in the MOX Fuel Line. Depleted uranium would be shipped via commercial carrier and stored outside the Superblock until needed in the MOX Fuel Line. To support a MOX Fuel Lead Assembly Mission, a MOX Fuel Line would be constructed in Room 1013 in the LLNL Plutonium Facility. The LLNL Plutonium Facility Increment 3 entrance and locker room would be used to isolate uncleared visitors and foreign nationals from nuclear weapons activities in Increment 1. In the MOX Fuel Line in Room 1013, the MOX pellets would be made, inspected, and loaded into rods, and the rods would be sealed and inspected (except for X-ray). The rods would then be overpacked and transported to Building 334, where the welds would be $X$-ray inspected and assembled into bundles, and the bundles would be stored. The MOX bundle assemblies would be shipped from Building 334 via SST.

LLNL has essentially all the support functions required to support a MOX Fuel Lead Assembly Mission at LLNL. These support functions include: security systems, qualified utility systems, fire-protection systems, analytical laboratories, waste-handling systems, up-to-date ES\&H documentation, and DOE-compliant MC\&A. The LLNL team has identified the following regulatory and permitting efforts that would be required for LLNL to accomplish a MOX Fuel Lead Assembly Mission: update NEPA documentation for Building 332 to cover MOX fuel fabrication; increase uranium limits for Building 332; and change the Building 334 Safety Analysis Report (SAR) for bundle assembly and storage. The LLNL departments that deal with the regulatory agencies do not feel that these changes are very significant. Areas where new functions are required or additional capacity is required include: MOX Fuel Fabrication Line, Bundle Assembly and Storage Facility, MOX fabrication expertise, and additional analytical equipment to support specificimpurity analysis. However, these areas are required by essentially all potential DOE facilities being examined, and the areas where LLNL plans to place the new equipment can be quickly reconfigured since the existing systems are noncontaminated.

LLNL appears to be a very attractive site for the MOX Fuel Lead Assembly Mission. LLNL management and DOE Oakland management have been informed of this potential project and are supportive.

\section{Facility Description}

\section{2a. Existing Facility Status}

Building 332, Increment III (Proposed for LA MOX fabrication)-The LLNL Plutonium Facility (Building 332) is a Nuclear Hazard Category 2 facility as determined by the methodology set forth in DOE-STD-1027-92, Hazard Categorization and Accident Analysis Techniques for Compliance with DOE Order 5480.23, Nuclear Safety Analysis Reports (December, 1992), and results of hazard 
and accident analyses detailed in Chapter 3 of the Plutonium FacilityBuilding 332 Safety Analysis Report (SAR) (January 1995). Currently the Plutonium Facility supports the DOE mission by:

- Developing plutonium-processing technologies for the Nuclear Weapons Complex Reconfiguration, Nuclear Material Disposition, and Stockpile Support Programs, and Defense Program (DP) waste cleanup and minimization.

- Developing improved plutonium pit safety features.

- Providing testing and surveillance of pits returned from stockpile.

- Reducing LLNL's excess plutonium and fissile uranium inventories.

- Functioning as the Laboratory's central repository for plutonium and fissionable uranium

Building 334, Engineering Test Bay (proposed for rod bundling, storage, and shipping)-The Hardened Engineering Test Building (HETB), Building 334, is a Nuclear Hazard Category 3 facility. An addendum to the facility's SAR will be required to raise the SNM limit to accommodate the program's needs. The Engineering Test Bay (one of two bays) is currently used to conduct thermal and dynamic tests on weapons components. The tests allowed within the facility are those involving either mock-explosive/mock-SNM or mockexplosive with SNM.

\section{2b. Previous Use}

Building 332, Increment 3-Increment 3 was constructed in 1977 to provide a capability for developing plutonium device parts in support of the Laboratory's Nuclear Test Program. Programmatic activities included:

- Machining and inspection.

- Density determinations.

- Welding techniques and welding parts.

- Assembly of devices.

- Pressure testing and gas fill operations.

In the early 1980s, the Special Isotope Separation (SIS) Program began research and development (R\&D) in the pyrochemical (i.e., non-aqueous) processing of plutonium in Increment 3 . The SIS Program also developed and constructed the Engineering Demonstration System (EDS) to demonstrate the full separator run cycle for a SIS plant using the Atomic Vapor Laser Separation (AVLIS) process. The EDS has operated only with nonradioactive rare earth materials (i.e., surrogates for plutonium) and has not been contaminated with plutonium. The system was not activated. 
Building 334, Engineering Test Bay-The activities in the Test Bay have not changed since the facility was originally authorized by DOE to conduct thermal and dynamic tests on weapons components.

\section{2c. Advantages for MOX Fabrication Utilization}

LLNL leads the Immobilization Program for the DOE Fissile Materials Disposition Program. The Immobilization Program recently selected ceramic as the form for plutonium immobilization. The process operations for ceramic immobilization are essentially the same as that for MOX fuel. LLNL has been building up expertise, experience, equipment, and supporting analysis systems for the Immobilization Program that are directly applicable to MOX Fuel. Current schedules show the Immobilization Program activities at LLNL decreasing in the year 2000. This corresponds to when the MOX Fuel Lead Assembly Mission would need to start operations. Therefore, a staff of fissile material handlers trained in fuel fabrication technology (cold press and sintering) will be available to support a MOX Fuel Lead Assembly Mission.

LLNL has an operational plutonium facility that handles Category 1 quantities of plutonium and has available space for additional missions. The available space contains noncontaminated equipment that can be easily removed at a relatively low cost. Using this space for the MOX Fuel Lead Assembly Mission would complement ongoing activities and help defray facility costs.

\section{Site Infrastructure}

\section{3.a Utilities}

Electrical Power-The primary source of electrical power for Building 332 is supplied by the Western Area Power Administration (WAPA), with Pacific Gas and Electric Company (PG\&E) as a secondary source. The electrical system provides power for all normal operations in Building 332. In the event of a partial or complete failure of the normal electrical system, an emergency power system provides power to essential selected loads. The emergency power system for Building 332 consists of two emergency diesel generators, automatic transfer switches (ATS), and one Uninterruptible Power Supply (UPS) for vital facility emergency systems, and one emergency generator, with ATS and UPS, for security.

Emergency Diesel Generators-The two facility emergency diesel generators have redundancy in case of the loss of any one generator. GDE 332-04 and GDE 332-07 are for building safety and are redundant. Diesel generator GDE 332-04 is located west of Increment 3, and diesel generator GDE 332-07 is located west of Room 1200.

Uninterruptible Power Supplies-The Uninterruptible Power Supply (UPS) includes two multiple-use battery/inverter systems. One system is used for 
building safety system service, and the other is used to supply power for security needs.

Water Supplies-LLNL receives domestic (city) water from the Hetch Hetchy aqueduct or from California Water District Zone 7. Domestic water enters Building 332 at the southwest corner of Room 1200 from a main on Second Street and also at the west stairwell airlock, adjacent to Room 1236, from a main on Third Street. The water supply system is an element of the firedetection and suppression system.

Ventilation-Air and inert gases used in glovebox operations and room air from the RMA are vented to the atmosphere by separate glovebox and room exhaust ventilation systems. Each system incorporates dual-stage highefficiency particulate air (HEPA) filters to minimize the emission of radioactive particulates to the atmosphere. Passive air samplers (PASs) and continuous air monitors (CAMs) are installed in the exhaust ducts downstream of the HEPA filters.

Because HEPA filters do not capture radioactive gases, operations that use or generate radioactive gases or vapors require special engineering controls, and approval by the Facility Manager to ensure compliance with the National Emission Standards for Hazardous Air Pollutants (NESHAPS)

Natural Gas-Natural gas is supplied to feed two boilers $(1,400,000 \mathrm{BTU} / \mathrm{hr}$ and 6,300,000 BTU/hr) for heating purposes. Operation of the two boilers is permitted by the Bay Area Air Quality Management District. There is no natural gas piped into the laboratories of the RMA.

Oxygen-Oxygen services are provided to Increment 1 for programmatic operations within the building. Four standard-size $\left(220 \mathrm{ft}^{3}\right)$ oxygen bottles, each having a cross-connection for mutual backup, are located outside the facility, on the west wall. A 1-in.-diameter line is routed from the bottles to a distribution manifold in the loft. Oxygen services from the distribution manifold are available to all rooms in Increment 1; however, current programmatic operations only require services to the Mechanical Technician Shop (Room 1305), the Scanning Electron Microscope Laboratory (Room 1313), and the Plutonium Recovery and Waste Handling Laboratory (Room 1378). Oxygen is supplied to these rooms at $40 \mathrm{psig}$. Programmatic operations within the rooms include oxygen/acetylene metal cutting.

Compressed Air-The compressed air system in Building 332 is a multipleredundant system used for both safety and non-safety functions. The system is used as a motive force for ventilation control components, for signal control and processing in the facility instrument subsystems, as the pressurizing agent for the fire-water storage tanks, for fire damper control and actuation, for programmatic application, and as a general-usage source from drop lines.

Vacuum-Building 332 requires vacuum service that can be considered in two categories: utility service that is permanently supplied to various laboratories 
for general needs, and programmatic service that generally entails individual or limited-distribution systems dedicated to a particular laboratory or process. Only the air-sampling service performs a safety function and is provided with emergency power. Vacuum pumps for programmatic experiments and processes are installed either in the laboratories or in a remote location determined by space requirements, noise levels, or other pragmatic considerations. Some pumps are fixed installations, while others are portable units that may be moved into a laboratory for short- or long-term use.

\section{3b. Security}

LLNL is a Class A facility, authorized to store and process Category I/II Special Nuclear Material (SNM). A well-defined, permanent Protected Area (PA) and Material Access Area (MAA) are located in the 330 Superblock, a $500-\mathrm{ft}$ by $700-\mathrm{ft}$ site. Included in the Superblock is Building 334, an authorized Category III storage facility.

Several security system upgrades are being implemented currently at Superblock as part of LLNL's Site Safeguards and Security Plan (SSSP) validation and approval process for FY98. These upgrades will sustain LLNL's Class A status against the DOE SNM protection requirements for Category I/II material.

The Category I requirements for the LAMOX can be completed within the MAA at Building 332, and contiguous to the LA proposed laboratory. Rod/bundle storage would be assigned to the Building 334 Category III facility.

Some physical security improvements would be required to accommodate LAMOX at Buildings 332 and 334, largely the expense of refurbishing an abandoned MAA entrance. This entrance would support LAMOX productivity independently from other LLNL missions at the MAA, and meet the requirement for secure and efficient access of uncleared and foreign visitors.

The LLNL Safeguards and Security Department (S\&SD) has the full range of required DOE functions: Protective Force, central clearance/visitor processing, foreign visits office, security education and awareness, physical and technical security, and a policy and planning group that conducts vulnerability analyses and completes the SSSP on a periodic basis. A resident counterintelligence office, computer security organization, and an MC\&A section work in concert with S\&SD to meet those requirements.

\section{3c. Fire Protection}

The Laboratory's in-house Fire Department Emergency Dispatch Center monitors facility health and safety alarms, answers 911 emergency calls, and dispatches personnel to fire, medical, and hazardous materials emergencies. The Fire Department is a participant in several levels of Automatic or Mutual 
Aid, with Agreements maintained with response organizations of Livermore, Twin Valley, Alameda County, State of California, and Alameda Emergency Service.

The Fire Department also provides advanced life-support paramedic ambulance services. Firefighters trained as paramedics and emergency medical technicians respond to medical emergencies and provide cardiac monitoring and defibrillation, intravenous access, administration of medications, and transportation of the sick and injured to the most appropriate receiving medical facility.

\section{3d. Analytical Laboratories}

Scanning Electron Microscope and X-Ray Analysis Laboratory (Room 1313)-This laboratory provides for $x$-ray spectrometric (chemical) and $x$-ray diffraction (structural) analyses of plutonium and other materials. Various $x$-ray spectrometers and diffraction instruments are used in this work. Room 1313A, which is within Room 1313, contains a scanning electron microscope (SEM).

Samples examined in the SEM are first cleaned in the ultrasonic cleaner in Room 1322 and then transferred in stainless steel cans to Room 1313B, where they are loaded into the SEM and analyzed.

A diagnostic tool (diamond cell) is used in this room to obtain static highpressure data on less than milligram quantities of plutonium and other actinide elements. A differential scanning calorimeter, which is used to perform thermal analyses on samples containing milligram quantities of plutonium and plutonium-bearing materials, is also located in this laboratory.

Other work conducted in this laboratory includes sectioning samples containing plutonium with a diamond saw and torch-sealing sample capillary tubes.

Analytical Chemistry Laboratory (Rooms 1321 and 1321A)-Workstations in this laboratory are used for preparing and analyzing plutonium-based samples or other actinides, alloy metals, and impurities. This laboratory has an openfront hood that is used for opening cans containing actinide samples transferred from the vault. Preparation of nonradioactive samples, standards, and very-low-activity alpha assay samples are also carried out in this hood.

Glovebox work activities include sample dissolution, chemical separations, and oxidation of plutonium metal. Emission spectroscopy is also performed. The direct current (DC) plasma spectrometer is used to determine trace quantities of impurities in plutonium samples. Room 1321A contains alpha- and gammaradiation counting equipment. 
Metallography Laboratory (Room 1322)-This laboratory provides the capability to conduct microstructural analyses of metals, alloys, and compounds in support of programmatic requirements. Operations in this laboratory include sample preparation of "cold" and radioactive materials, encapsulating, cleaning, electropolishing, microhardness testing, photomicrography, and photographic processing. Specimens are then archived or unencapsulated for SNM recovery.

Analytical Chemistry Laboratory (Room 1329) - This laboratory is used for cutting and sorting actinide (primarily plutonium) samples and preparing them for analysis for gamma-ray spectroscopy, mass spectroscopy, emission spectroscopy, gas analysis, and plasma spectrometry. In addition to gloveboxes, this room has an open-front hood, used for opening cans containing materials transferred from the vault or other laboratories. Preparation of nonradioactive samples, standards, and very-low-activity alpha assay samples is also carried out in the hoods.

This laboratory contains three nitrogen-atmosphere gloveboxes that are used for cutting, sorting, and weighing. Dissolution and chemical separation of samples are performed in Workstation 2903 (wet chemistry analytical line). A caustic wet scrubber is attached to this workstation to remove acid fumes from the glovebox exhaust.

Two air-atmosphere gloveboxes in this laboratory contain gas analyzers for determining the carbon, sulfur, nitrogen, oxygen, and hydrogen content in samples of metals, powders, and salts.

Microprobe Laboratory and Sputtering Facility (Rooms 1330 and 1330A)Room 1330 contains a sputtering facility and a sputtering shield cleaning facility. These facilities, which produce materials needed for research, provide a high-rate sputtering source for projects requiring the deposition of thin films. The process uses a triode sputtering system, which is capable of sputtering any metallic element or alloy, and can safely sputter materials bearing alpha activity. This sputtering system is enclosed in a vacuum chamber that is located inside a glovebox.

The cleaning facility provides a means of removing residual films after chemical dissolution of plutonium and other sputtered metals have been deposited on the shields. Removal of films, by glass bead blasting and ultrasonic cleaning, is required before the shields can be reused in the sputtering chamber. This work is conducted inside gloveboxes.

Room 1330A provides a location for $x$-ray microanalysis of plutonium and plutonium alloys. These analyses are used in conjunction with optical metallography to characterize materials. This work includes the preparation of samples in a carbon evaporator and the observation and recording of the composition and topography of plutonium and plutonium-based materials in the electron microprobe. 
Samples for these analyses are first cleaned in the ultrasonic cleaner located in Room 1322 and then transferred to this laboratory for microprobe examination.

Inspection Laboratory (Room 1362)-This room contains equipment in gloveboxes that is used to make precision measurements and inspections on plutonium-bearing parts to verify they meet design specifications.

Approximately $90 \%$ of the work performed in this room is on classified parts.

The following equipment is contained within individual gloveboxes:

- Sheffield Rotary Contour Gauges-Two of these gauges are contained in one glovebox and are used to inspect the radii and wall thicknesses of parts. One of the gauges is computer controlled while the other is manually controlled.

- Moore Measuring Machine-This equipment can be used as a radius gauge to measure spherical parts, as a surface analyzer to measure surface finishes of machined parts, and to inspect diameters of plutonium spheres by the point-to-point method.

- Surface Plate-With a precision flat granite base, this glovebox contains precision tools and gauges used to inspect plutonium parts. Machined parts are checked for heights, diameters, and positional accuracy of steps or drilled holes using height gauges, gauge blocks, micrometers, or calipers.

- Surface Analyzer-A Class II laser, mounted on a precision flat granite base, is used to inspect surface finishes of machined plutonium parts. These parts are inspected for roughness average and profile of curved and flat surfaces.

- Balance Box-Electronic balances in this box are used to weigh plutonium parts for programmatic inventory control in the range between a few grams to about five kilograms.

\section{3e. Waste Handling}

The facility's waste management team is responsible for ensuring that the facility's radioactive waste is handled and processed in accordance with the LLNL Waste Certification Program and all state and federal mandates, and that it meets the requirements of the Waste Isolation Pilot Plant (WIPP) and Nevada Waste Disposal Site.

The Laboratory's Environmental Protection Department (EPD) supports facility operations by providing guidance on waste packaging and labeling requirements, and by managing the disposal of these wastes: low-level (LL) radioactive, transuranic (TRU), mixed, and hazardous. In addition, EPD monitors the compliance of building operations with National Emission Standards for Hazardous Air Pollution (NESHAP), obtains permits and exemptions for pollution-emitting programmatic and facility equipment, and prepares and processes National Environmental Policy Act (NEPA) documentation in accordance with DOE guidance. 


\section{3f. Support Systems}

The work of the Plutonium Facility is accomplished through a network of Laboratory organizations and responsible individuals. The organizational structure of these organizations and individuals, their responsibilities, and their interfaces are described in the following paragraphs.

Organizational Structure-The primary organizational elements operating in and supporting the Plutonium Facility are from the following directorates: Defense \& Nuclear Technologies, Plant Operations, Chemistry and Materials Science, Engineering, and Laser Programs.

ES\&H, Plant, and QA Support Organizations-These organizations provide ES\&H and technical support to facility staff and to programmatic users of the Plutonium Facility. Utility services, along with institutional support, are provided by the Plant Engineering Department. Fire and medical response services are also a part of the Plant Operations Organization.

Hazards Control Department-The Hazards Control Department (HCD) supports Building 332 operations by identifying hazards, assessing risks, performing safety analyses and preparing required safety documents, assisting in Unreviewed Safety Question (USQ) determinations, monitoring the work environment, participating in safety reviews of planned and ongoing program operations, and advising the Facility Manager on appropriate safety measures under normal and emergency conditions.

Health Services Department-The Health Services Department (HSD) provides initial medical treatment for injured or contaminated personnel, approves the use of respirators and self-contained breathing apparatus (SCBA) by facility personnel, and provides regular physical examinations for the LLNL workforce.

Plant Engineering-Plant Engineering's Maintenance/Operations Department performs preventive maintenance and on-demand repair of building safety, utility, and service systems, and also provides custodial services and crafts support for the facility.

Safeguards and Security Department (S\&SD)—Protective Service Officers (PSOs) from S\&SD's Protective Force Division provide continuous security for the Plutonium Facility. PSO's control access to the Radioactive Materials Area (RMA) and to the Protected Area that surrounds the facility, and conduct required searches of vehicles, personnel, and packages.

Assurance Managers-The Assurance Manager's duties include assisting the Associate Director (AD) in developing plans and procedures to assure that all directorate activities comply with LLNL and directorate ES\&H policies, and performing independent assessment of the ES\&H program within the directorate. 
Assurance Review Office-The role of the Assurance Review Office (ARO) is to conduct independent evaluations of LLNL's Environmental, Safety, and Health (ES\&H) and related Quality Assurance (QA) systems in order to determine conformance with the Laboratory's ES\&H policies and procedures and applicable ES\&H laws, regulations, and directives.

Laboratory Assurance Office-The Laboratory Assurance Office (LAO) consists of the Quality Assurance Support Office and the Human Reliability Programs Office. Through the QA Support Office, the LAO provides support to LLNL organizations in QA training, audits, and appraisals, and wastemanagement issues.

Criticality Safety-The Criticality Safety Group provides support to activities by reviewing ongoing and new operations and formulating criticality safety controls. This group also performs audits and inspections of facilities or operations involving fissionable materials. These audits are conducted to verify that applicable safety procedures and other safety standards are being followed, and to identify any weakness in the safety control systems.

\section{3g. Regulation \& Permitting}

LLNL's Environmental Protection Department supports the facility to ensure that its operations are performed in a manner consistent with environmental laws, regulations, and DOE Orders, and is responsible for obtaining any necessary environmental permits. An Environment, Safety, and Health Team, comprised of environmental specialists and technicians, provides the key interface between the facility and ES\&H support organizations.

The ES\&H Team's responsibiities include: providing ES\&H technical support during normal operations and emergencies; assisting in identifying, analyzing, and minimizing hazards and environmental concerns; assisting in environmental compliance actions; obtaining environmental permits and variances as needed; advising line organizations of applicable ES\&H codes, standards, regulations, and DOE Orders in a manner consistent with Laboratory policy, and assist line organizations in meeting mandatory requirements; monitoring the work environment for compliance with the LLNL Health and Safety Manual, LLNL Radiological Control Manual, LLNL Environmental Compliance Manual and Environmental Guidelines, applicable safety procedures, codes, standards, regulations and DOE Orders, and advise management on noncompliances.

LLNL currently operates a hazardous waste treatment storage and disposal facility (TSD) under interim status regulations (40 CFR 265 and 22 CCR 66265). A hazardous waste permit for operation under Resource Conservation and Recovery Act (RCRA) "Part B" requirements (40 CFR 264 and 22 CCR 66264) is anticipated in 1998 for a replacement facility (Decontamination Waste Treatment Facility (DWTF)). Various storage and treatment units in the currently operating facility will be closed over a transition period once the DWTF becomes operational. 
The current facility accepts a variety of waste types, including RCRA hazardous waste, RCRA mixed waste, low-level radioactive waste (LLW), and transuranic solid waste (TRU). LLNL is currently under negotiation with the California Environmental Protection Agency, Department of Toxic Substances Control (DTSC) for the management of "combined waste," i.e., low-level radioactive waste and/or TRU waste with California hazardous constituents.

Various forms of LLW are treated at the current hazardous waste management facility and the proposed DWTF will also be capable of treating specific hazardous, mixed, and LLW wastes. Onsite TRU waste storage is available. No waste treatment by incineration is currently available onsite, nor will it become available due to regulatory issues and public concern. Any waste entering the DWTF must meet Part A permitting requirements and Waste Acceptance Criteria. Published Waste Acceptance Criteria is available from HWM for all accepted waste streams (hazardous, LLW, TRU, special case waste, etc.)

\section{3h. Safety}

The ES\&H team supports the facility by assisting in the development and review of safety-related procedures and documents, assisting the facility in identifying and analyzing hazards and environmental concerns in programmatic and facility operations, advising facility and programmatic operations management of appropriate controls to eliminate or minimize the identified hazards and environmental concerns, monitoring the work environment for compliance with the appropriate codes, standards, and applicable safety procedures and advising management of noncompliances, providing technical support during normal operations and emergencies, assisting facility and programmatic operations management during the analysis of accidents or incidents, and observing work practices to ensure exposures to radiation and toxic agents are as low as reasonably achievable (ALARA).

\section{3i. MC\&A}

The nuclear material measurement equipment on site is adequate for measuring the raw materials input to the LA MOX project; i.e., plutonium oxide and low-enriched uranium (LEU) oxide. However, standards representative of the LEU oxide are required to calibrate instruments for good accountability measurements. LLNL has standards adequate for measuring the plutonium oxide. LLNL does not have measurement equipment adequate for measuring the finished fuel rods. The MOX pellets could be measured before loading in fuel rods, but again, standards representative of the pellets would be needed to calibrate instruments for good accountability measurements. If measurements of the finished product are required, LLNL will have to procure either an Active Well Coincidence Counter (AWCC) that can be configured to count fuel rods piecewise or a rod scanner. In either case, LLNL will have to obtain/develop representative standards. 
All other aspects of the MC\&A system are adequate, although depending on the scale of the project, some computer system upgrades for the MC\&A database system may be required.

\section{Process Interface Descriptions}

\section{4a. Feed Material Receiving}

The receipt of the feed material at LLNL would be handled like any other SST receival. Materials Management at Livermore would have 741 forms, authorization-to-ship documents, and transportation dates from Albuquerque TSD. Shipper/receiver documentation for MC\&A accountability and measurements would have already been established.

The feed material would undergo some agreed-upon form of NDA analysis within the time frame established for verification/confirmation measurements specified in DOE 5633.3B or the then-current MC\&A order. The empty DOT containers would be returned to sender.

\section{4b. Feed Storage}

Following receipt of the material as described above, this material would then be placed in storage. The storage vault is a Category 1 storage location and has various safeguards and security protections. Measured material would be placed in storage and delivered to the MOX workstation as requested.

\section{4c. Blending}

The given assumptions are that the feed $\mathrm{PuO}_{2}$ and $\mathrm{UO}_{2}$ will be provided from a separate vendor and will be in compliance with specifications regarding $\mathrm{O} / \mathrm{M}$ ratio, particle size distribution, and impurity content. In the case of $\mathrm{UO}_{2}$, an additional assumption is made that the $\mathrm{UO}_{2}$ is formed using the MOX vendors' proprietary specifications regarding source processing, flowability, pressing characteristics, and sinterability. The $\mathrm{PuO}_{2}$ will be obtained from the LANL AIRES demonstration line and will be prepared using the HYDOX process.

In considering the blending operations, it is recognized that there are potential differences, depending on the MOX vendor selection, which could result in either the sort binderless route from BNFL or the MIMAS process from either Belgonulceaire or Cogema. For purposes of our implementation description, we are following the ORNL guidelines, and we will consider implementation of only the MIMAS process.

The basic blending, pellet fabrication, and rod loading operations require approximately $2000 \mathrm{ft}^{2}$. Additional space is required for the various inspection, assay, and storage operations which sum approximately $3000 \mathrm{ft}^{2}$. The core operations will be installed in the existing Room 1013 area of Increment 3 of the LLNL Plutonium Facility. This room is $3200 \mathrm{ft}^{2}$ and will easily accommodate 
the core processing and assembly operations as well as select inspection and storage functions. Possible layouts are shown in the appendix to this document.

A key facility for conduct of the MOX pellet fabrication operations is a properly equipped analytical facility. LLNL currently has on the order of $3000 \mathrm{ft}^{2}$ of analytical space, which includes a full-service metallography facility with a scanning electron microscope and electron microprobe, as well as analytical capabilities for the full range of impurities, mass spectroscopy analysis, and isotopic analysis. In addition to these capabilities, LLNL has crystallography facilities for X-ray diffraction analysis and particle-size analyzers, including laser scattering and BET. Note that these facilities have been developed to support a full-service weapons $R \& D$ facility which manufactured a range of metal parts, provided chemical processing and purification operations, and conducted $R \& D$ on a wide variety of topics in plutonium chemistry and metallurgy.

The incoming $\mathrm{PuO}_{2}$ and $\mathrm{UO}_{2}$ batches will be opened in a can receiving area and assayed to ensure that feed batch specifications are being satisfied. All operations will be performed in nitrogen boxes to minimize excess water adsorption. Acceptable cans of feed material will be re-stored in closed containers pending transfer to the batching and blending operations. These inspection operations will be co-located with the batching and blending operations since they are part of the incoming feed inspection and quality control inspections, and the plutonium and uranium from these operations will be stored in sealed containers prior to batch makeup for the master blend formation operation.

All gloveboxes used for batch makeup and blending will be nitrogen-flush boxes to minimize water pickup of the powders. All boxes, beginning with batch makeup, will be located within the Room 1013 facility and will be interconnected with appropriate transfer systems to avoid breaking containment during these operations. The only exception will be the transfer of sample bottles to the analytical facility at appropriate steps in the operation.

The blending operations first require the production of a Master Blend (MB) consisting of $30 \% \mathrm{PuO}_{2}$ in a $\mathrm{UO}_{2}$ matrix. The primary source of materials for this master blend will be the incoming $\mathrm{PuO}_{2}$ from $\mathrm{LANL}$ and the vendor supplied $\mathrm{UO}_{2}$. In actual implementation, varying quantities of recycled $\mathrm{UO}_{2} / \mathrm{PuO}_{2}$ material may be used in making up the $\mathrm{MB}$.

The blending for the MB will first be established by making up a batch of the characterized feeds as determined by analysis of the incoming oxide feed materials. Adjustments will be made to achieve $30 \% \mathrm{PuO}_{2}$ and specified quantities of recycle material as determined by the vendor. This batch, subject to criticality limits of likely $4 \mathrm{~kg}$ Pu total, will be placed into a high intensity ball-mill system as specified by the vendor and milled to the vendor specifications. The product of this blending will be a micro-blended mixture of $\mathrm{PuO}_{2}$ and $\mathrm{UO}_{2}$ as specified by the $\mathrm{MOX}$ vendor. The product will then be 
sampled and analyzed using LLNL analytical facilities for compliance with product specifications. Corrections to the MB can be made as appropriate in order to obtain an adequate product. When MB specifications are satisfied, the blended product is then transferred into smaller batching cans for subsequent addition of the $\mathrm{UO}_{2}$ to make up the MOX batches in preparation for pellet fabrication. These smaller batching cans are then stored in an in-line storage box in the blending line pending their use in making up the MOX fuel blend.

The next operation will be the makeup of a MOX pellet blend which corresponds to the specifications of the reactor operator regarding isotopic content and $\mathrm{PuO}_{2}$ loading. Batched cans of the $\mathrm{MB}$ prepared and characterized earlier will be loaded into a blender along with the appropriate quantities of the $\mathrm{UO}_{2}$ feed material. A coarse blending will be performed, and a powder sample will be taken to check the blend makeup compliance with specifications. Adjustments will be made as appropriate, depending on analytical results. Additions of appropriate binders, pore formers, and die lubricants according to MOX vendor and reactor operator specifications will be made. Additional low-energy blending will be performed, and an additional powder sample will be pulled for fabrication of a test series of pellets. The small press and sintering furnace for this operation will be a collocated box in the batching and blending line. Product pellets from this operation will be analyzed in the LLNL Analytical Facility for density, size, and defects. If acceptable, the blended batch is then ready for transfer into cans for transfer to the pellet fabrication operations. If not, additional corrections will be made to the blended batch or recycle of the batch will be made as appropriate.

It should be noted that LLNL, as the lead laboratory for the immobilization of $\mathrm{Pu}$ using the ceramic waste form for disposition, will have an operating facility by 1999 for the limited demonstration of ceramic waste form production and qualification through the year 2001. The process operations for ceramic production incorporating $\mathrm{Pu}$ are closely matched to those for $\mathrm{MOX}$, and involve feed characterization, milling to specifications, blending with precursors on a micro-scale, pressing, and sintering. The quality of the sintered form must be controlled for repository qualification, though dimensional specifications are less stringent than those for MOX. The facility for ceramic immobilized form production will not be in the same room, but will be close by. This ceramic immobilization facility will provide considerable experience in the conduct of the MOX operations and will be a backup and R\&D facility capable of supporting the MOX LA mission.

\section{4d. Pellet Production \& Inspection}

Pellet production and inspection operations will be collocated in the

Room 1013 facility with the batch makeup and blending operations. The pellet production gloveboxes will be connected to the batch makeup and blending boxes with the appropriate transfer connections such that bag-ins and bag-outs are not required. In addition, all pellet production operations will be appropriately interconnected to facilitate powder and pellet transfer without breaking containment. 
The containers containing the conditioned and blended feed that has been previously qualified with test sintered pellets will be transferred to the feed hopper of the press which has been set to the pellet-pressing specifications. A brief test run will be made, and the green pellets will be analyzed for defects, weight, and dimensions. The batch will then be pressed and the pellets transferred to the inspection box where appropriate sampling and in-line analysis will be performed prior to sintering. Rejects and unpressed powder will be sent back for recycle or discard as appropriate.

Qualified pellet batches will then be prepared for sintering. It is assumed that a horizontal pusher furnace will be specified by the MOX vendor and will be continuously operating according to vendor specifications regarding temperature profile and atmosphere. The pellets will be loaded into boats and processed through the furnace cycle as specified.

Product pellets from the sintering operation will be loaded into transfer baskets and moved to the inspection/grinding box. Samples of the pellets will be analyzed to ensure the attainment of sintered pellet specifications, including analytical analysis. The pellets will then be centerless ground to the specified dimensions in the grinding box. The ground pellets will then be transferred to the inspection station, where each pellet will be measured for dimensional specifications and roundness. Appropriate numbers of pellets will be taken from each batch and analyzed in the metallography facility and analytical facility to ensure compliance with final specifications. After a batch has been qualified, they are then stored in an in-line storage area prior to being transferred to the rod-loading facility, which is also contained within Room 1013.

Pellets that are rejects from the inspection operations, as well as residue from the centerless grinding, are sent to a recycle box. Here the pellets for recycle, or other materials, are either reground in a jaw crusher/milling station prior to transfer back to the receiving station for analysis and batch makeup or are sent to a packaging box for canning and assay prior to transfer to the immobilization program.

\section{4e. Rod Assembly \& Inspection}

The rod-assembly gloveboxes will be set up in Room 1013 in conjunction with the balance of the pellet fabrication facility and will be interconnected to the pellet-inspection station. Since rod assembly seals the pellets in the stainless fuel pin, it will not be mandatory to include all the follow-on rod inspection operations within in the same room (with the exception of ensuring that the rod is sealed and not contaminated).

In operation, batches of pellets are received in the rod assembly station from the pellet-fabrication operations. The pellets are loaded into columns on trays in preparation for insertion into the rods. New rods are inserted into the assembly station, and pellets are loaded into the rod. Sufficient horizontal space is required for loading and handling as well as a glovebox/hood 
operation for rod insertion and loading. After the rods are loaded, springs are inserted, and the end caps are inserted. The rod end is then decontaminated and moved to the welding and leak-check area, where the end caps are welded in place, the rod is flushed with $\mathrm{He}$, pressurized with $\mathrm{He}$, and sealed.

Following leak-checking, the rod will be inspected by passive/active neutron scanning and gamma scanning, and rolled on a surface table. The rod will then be placed into a storage rack. The rods will then be overpacked and transferred to Building 334. X-ray weld inspections will be performed in Building 334 after the rod is transferred.

\section{4f. Rod Storage}

Fuel rods will be stored in the rod storage area in Building 334. This function will interface with Rod Fabrication and Bundle Assembly.

In Building 332, Room 1013, the accepted rods will be loaded into a shipping container. The container will transported to the Rod Storage Area in B334 via the East Portal of B332. Upon arriving at the storage area, the rods will identified and logged into the inventory system. They will then be stored in horizontal racks or trays until requested for bundle assembly, to which they will be transported horizontally via a cart.

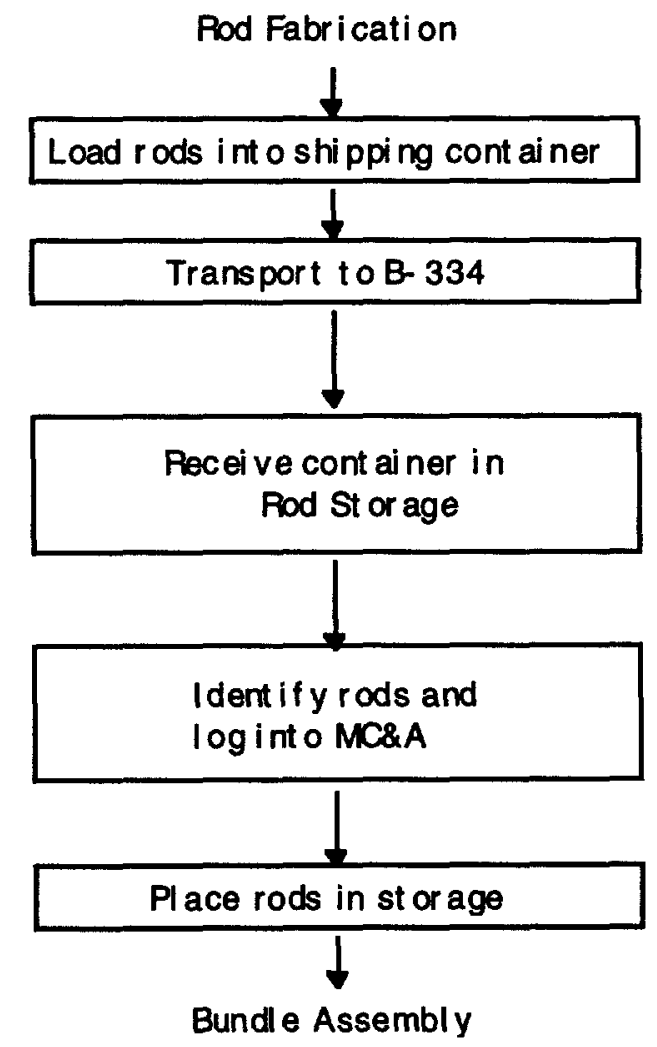




\section{4g. Bundle Assembly}

Fuel bundles will be assembled in B334.

Rods will be requested from Rod Storage. The rods will be identified, loaded onto a cart, and taken to the Bundle Assembly area. Their identity will be confirmed before unloading them onto the Setup Station. The rods will be loaded horizontally into the Bundles in the Bundle Assembly Area. The Bundles will then be tipped to a vertical position and transferred with the overhead hoist to the Bundle Storage Area.

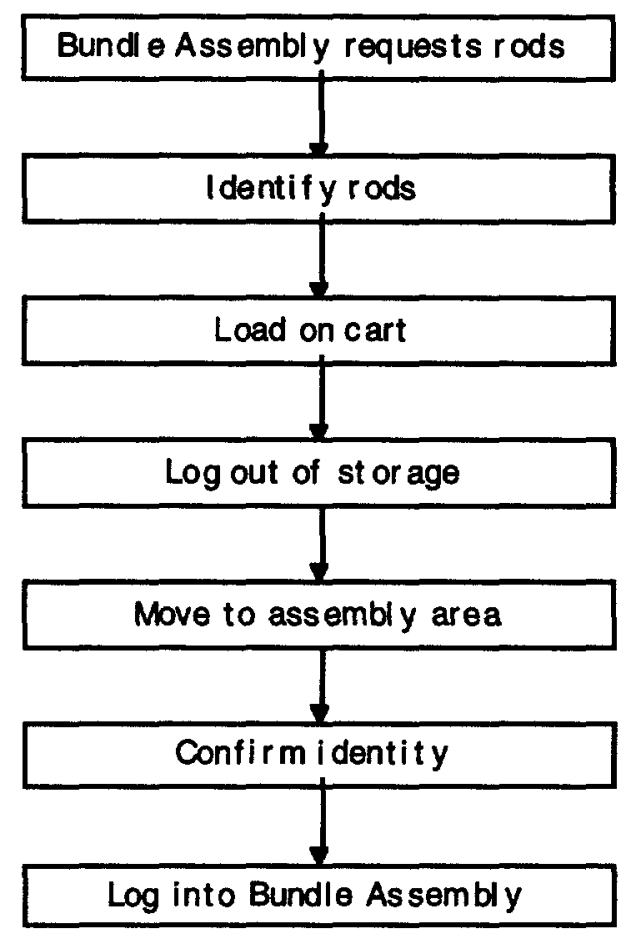

\section{4h. Bundle Storage}

Fuel bundles will be stored in a seismically qualified rack mounted on the south wall of B334, Room 1008.

After the bundle is accepted, it will be transported to the storage rack by overhead crane. The pins will be logged out of the assembly area and into the Bundle Storage area. Upon request for shipping, the bundle will be identified, loaded into the Shipping Container, identity reconfirmed, and logged out of the storage area. 


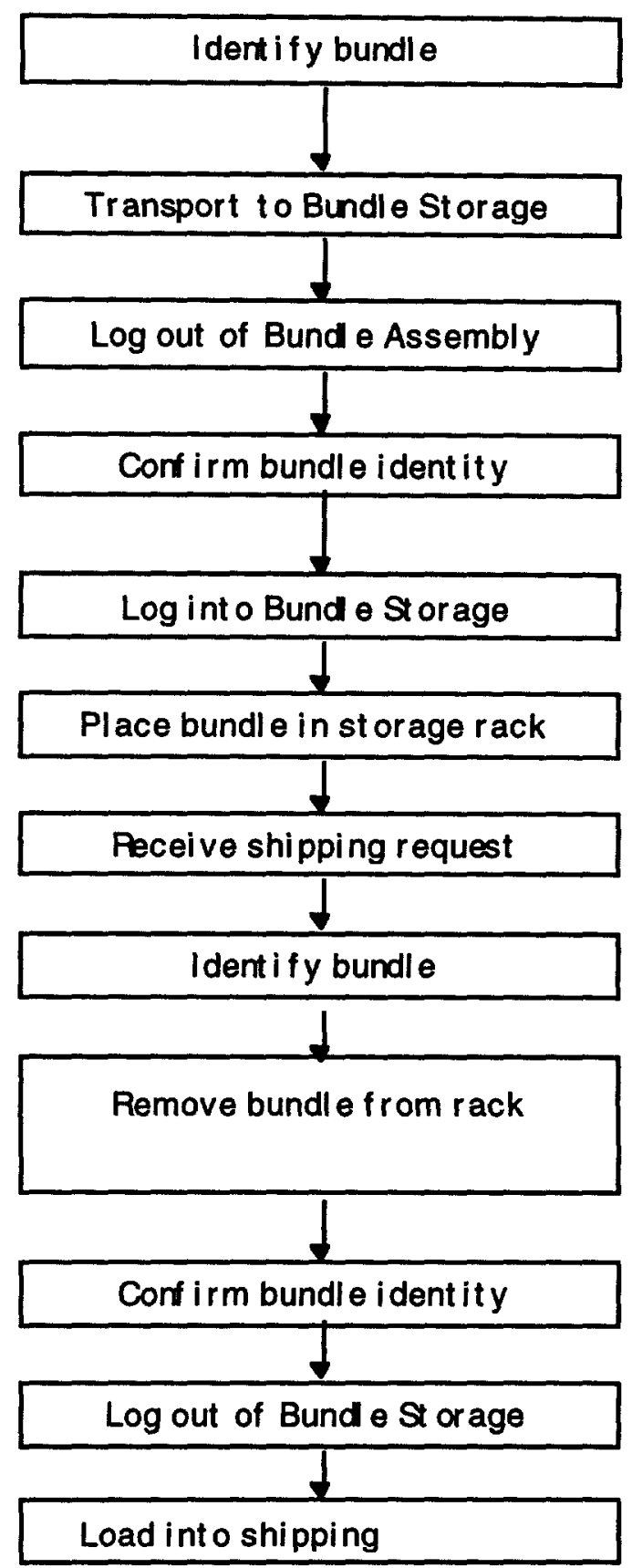

\section{4i. Packaging and Shipping}

The packaging and shipping of the bundles would be accomplished by Materials Management.

All of the transportation scheduling, proper shipping and MC\&A documentation, loading, and security would be accomplished by the LLNL Materials Management Operations group. The loading of the SST would occur at Building 334. This building is where the rods would be loaded with the final shipping assembly. Proper loading of the assembly onto an SST would 
probably require purchase of some new loading equipment if the MO- 1 were the container of choice.

\section{4j. Waste Handling}

Any reject materials, impure oxides, or glovebox sweepings will be transferred to the Materials Processing Laboratory (MPL), Room 1010, and calcined. These materials will then be loaded to long-term storage cans for shipment to the Immobilization Facility. Used or broken contaminated equipment will be placed into 55-gallon drums as TRU waste and removed from Building 332 and stored for eventual disposal at WIPP. Uncontaminated material from rooms within the Building 332 RMA will be treated as LLW and packaged into 55-gallon drums for disposal at the LLW disposal site. Solutions from analytical chemistry operations will be processed in the Recovery Laboratory, Room 1378. This processing involves removal of plutonium from the solutions and cementation of the remaining liquids. The cemented liquid waste is then placed into TRU waste drums.

\section{Proposed Facility Modifications}

\section{5a. Modifications Required To Install MOX Fuel Fabrication Equipment}

MOX Fuel fabrication equipment would be installed in the following Superblock buildings: Building 332, Building 334, and Building 335. Specific modifications to each building are detailed below.

\section{Building 332 Modifications}

The major modification to Building 332 would be to the south end of Increment 3, where the MOX Fuel Line would be installed. This area of Building 332 is divided into four rooms with sheetrock walls. Essentially all of the equipment has been removed from the three smaller rooms (Rooms 1005, 1013 , and 1005A). The equipment remaining in the larger room (Room 1009) consists of empty, noncontaminated gloveboxes. To accommodate the MOX Fuel Line, the sheetrock dividing walls and the gloveboxes would be removed. The gloveboxes would be used elsewhere on site or sent to salvage. The cleared-out space is a room $40 \mathrm{ft}$ by $80 \mathrm{ft}$, which for this document will be designated as Room 1013.

The MOX Fuel Line would be installed into Room 1013 and consist of the following gloveboxes:

1) Plutonium Oxide Receiving and Inspection

2) Plutonium Oxide Storage

3) Master Blend/Mill

4) Overhead Transport Tunnel

5) Final Blend 

6) Prepress (slug)
7) Granulate
8) Press
9) Sinter
10) Grind
11) Inspect Pellets
12) Store Pellets
13) Rod Loading

In addition to these gloveboxes the following equipment areas are outlined:

1) Rod Loading Area

2) Rod Weld, Pressurize, and Leak Check

3) Passive/Active Neutron Scan

4) Gamma Scan

5) Surface Table

6) Rod Storage Area

7) Uranium Oxide Receipt, Inspection and Storage

Figure 1 (figures are in the appendix) shows how these gloveboxes and equipment areas would be laid out into Room 1013. Support equipment such as control panels would be placed under the gloveboxes. Larger support equipment such as gas purification units and furnace controller would be located in the basement below Room 1013. Glovebox exhaust would be tied into the existing Increment 3 glovebox exhaust system.

To isolate uncleared visitors and foreign nationals from nuclear weapon activities, the Increment 3 entrance into Building 332 would be reactivated. This will require installation of a new portal monitor for this entrance.

LLNL would need to install the following additional analytical instruments in addition to those installed as part of the MOX Fuel Line: ICP Mass Spectrometer, Thermal Ion Mass Spectrometer, and Ion Chromotography. These instruments would be installed in the current analytical laboratories located in Rooms 1313,1321, and 1329. LLNL is currently installing a BET system for powder surface area determination and a laser scattering particle size analyzer.

\section{Building 334 Modifications}

Building 334 has two large bays; the East bay, Room 1008, would be used for rod storage, $X$-ray inspection, bundle assembly, and bundle storage.

Room 1008 is approximately $40 \mathrm{ft}$ by $50 \mathrm{ft}$ and has large vault doors that allow large vehicles to drive into the building. For the MOX Lead Assembly Mission, 
the current equipment in Room 1008 would be removed and used elsewhere on site or sent to salvage. Figure 2 shows how Room 1008 would be configured for the MOX Lead Assembly Mission.

\section{Building 335 Modifications}

Building 335 is a $12,000 \mathrm{ft}^{2}$ building that is adjacent to Building 332 . It contains change rooms, assembly areas, office space, file rooms, and storage areas. In Room 1110 of Building 335, areas would be set up to receive hardware for rods and to weld the first end plug into the rods. Figure 3 shows how a section of Room 1110 would be configured for the MOX Lead Assembly Mission

\section{5b. Modifications Required To Accomplish DOE Order Compliance}

No modifications are required to Buildings 332 or 335 to meet DOE Order compliance. The only potential modification that has been identified for Building 334 is a criticality alarm system. However, due to the nature of the MOX fuel rods being stored and assembled in Building 334, a criticality alarm system may not be required.

\section{Resources and Manpower Discussions}

The manpower numbers shown in the following table are for direct labor for design, construction, and operations. Supporting labor for training, safety oversight, facility operations, security, etc., are estimated to be about 2 to 3 times the direct labor.

Direct Labor Resource Summary

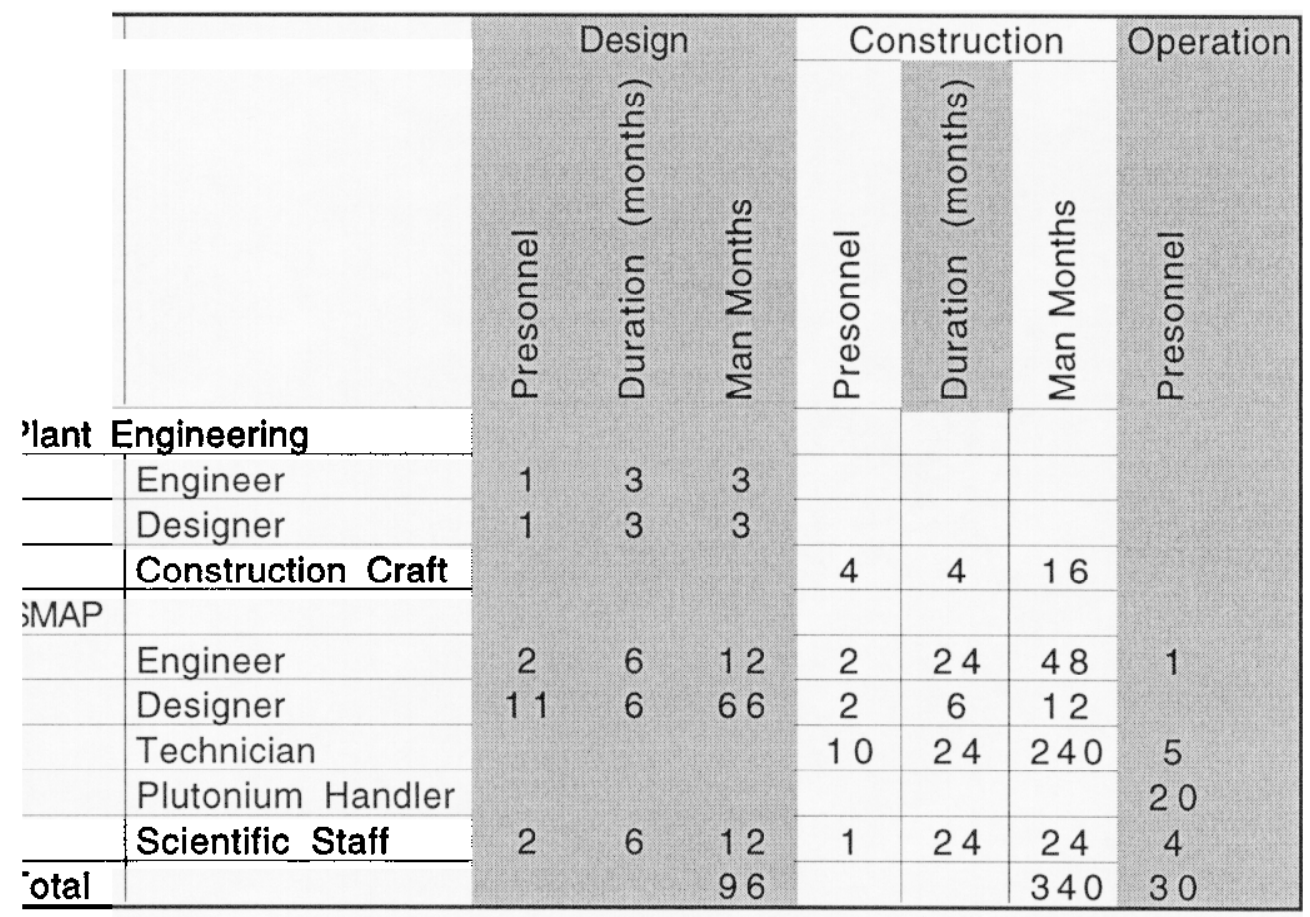




\section{6a. Design}

LLNL assumes that the Lead Assembly equipment will be specified by the MOX Fuel Vendor and placed into gloveboxes designed by LLNL. If the MOX Fuel Vendor designs the glovebox, then the LLNL design manpower requirements would be significantly less. The major design tasks are for Building 332, Room 1013, and Building 334, Room 1008

B-332, Room 1013 preparation-This task will be done by Plant Engineering personnel. It consists of preparing demolition drawings specifying the removal of existing "cold" gloveboxes, removal of non-bearing walls, relocation of HVAC ducts, evaluation of the existing sprinklers, and relocation of facility utilities.

LTA equipment installation-This task will be conducted by the Strategic Materials Application Program (SMAP) engineering team. Gloveboxes and equipment to support the installation and operation of the LTA equipment will be designed. Supporting utilities such as glovebox ventilation connections and atmospheric control will be specified.

B334, Room 1008-This task will be done by Plant Engineering personnel assisted by a SMAP design engineer. Existing equipment removal will be specified. A seismic analysis of the exterior wall and the design of the bundle storage rack will be done.

Manpower: 96 man months

Duration: 6 months

\section{6b. Construction}

B332, Room 1013 preparation-This task will be done by Plant Engineering personnel and the LLNL pool of "Labor Only Contractors." Existing equipment will be disassembled and removed. The non-bearing walls separating the laser area from the main room will be removed, providing a single $3200 \mathrm{ft}^{2}$ room. The HVAC ducts will be relocated as necessary, as well as the fire sprinklers. Existing utilities will be relocated and new utilities added as required.

LTA equipment installation-This task will be conducted by the Strategic Materials Application Program (SMAP) engineering team consisting of engineers, technicians, and Plant Engineering crafts. The Operations Team will be involved and, during equipment checkout, will accept the equipment. The equipment and gloveboxes will be staged in an unclassified "red" area where vendors, suppliers, and consortium members will have free access. After the equipment is installed in the gloveboxes, it will be checked for operability and moved into Room 1013. Seismic anchoring and utility connections will be done by Plant Engineering crafts. Equipment and process installations and checkout will be done by SMAP technicians. 
B334, Room 1008-This task will be done by Plant Engineering personnel. Existing equipment will be removed, A seismically qualified bundle storage rack will be mounted on the south wall. Bundle assembly equipment will be installed and seismically anchored.

Manpower: 340 man months

Duration: 24 months

\section{6c. Operation}

This task will be conducted by a SMAP team consisting of plutonium handlers and technicians, supported by chemists and engineers, and the facility and site infrastructure.

Manpower: 30 FTEs while operating

Duration: As required

\section{Environmental Compliance}

Environmental compliance requirements and LLNL's responsibilities, policies, and procedures are detailed in several documents including the Environment, Safety and Health Program at the Lawrence Livermore National Laboratory, and the LLNL Environmental Compliance Manual. The 1992 Final Environmental Impact Statement and Environmental Impact Report for Continued Operation of Lawrence Livermore National Laboratory (1992 EIS/EIR) provides a summary of laboratory activites, their potential environmental impacts, and measures undertaken to mitigate those impacts.

\section{7a. Permitting}

MOX LA Fabrication at LLNL will require additional site-specific NEPA analysis; probably at either an Environmental Assessment (EA) level, or by incorporating the project into a possible supplement to the 1992 EIS for continued operations at LLNL. It must be noted that no decision has yet been made as to whether a supplement is needed. If a supplement is needed, the process would likely begin by early CY98 and would take approximately 18 months to complete. Alternatively, an EA for this effort would likely take 9-12 months, given the nature of the project.

Based upon current information on waste types to be generated at the MOX Lead Assembly Fabrication Facility, LLNL will be capable of storing and treating some forms of LLW, depending upon hazardous and radioactive content meeting waste acceptance criteria including, radionuclide concentrations, criticality safety ( 120 grams of fissile isotope), surface dose rate, etc. If additional treatment permits/modifications for such processes as solidification of TRU/mixed waste, it will take a minimum of 2 to 3 years to prepare and acquire a DTSC treatment permit in the generator area or a modification to the DWTF hazardous waste permit. Wastewaters generated from process areas will also have to be evaluated against LLNL's required 
discharge limits. LLNL is currently permitted to discharge to the City of Livermore's wastewater treatment facility (POTW) under permitted discharge limits. At this time, the proposed MOX LA mission is not expected to require any new permits or modifications to any of the existing air permits.

\section{7b. Effluent Monitoring}

Air discharge points are monitored by alarmed Eberline CAMs and also by simple filter-type aerosol collection systems. The latter are also continuous collection systems but are not alarm systems. The Eberline monitors provide the alarm capability for the facility. Alarms from the Eberline monitors are automatically routed to the facility's control room and also to the LLNL Sitewide Alarm System Emergency Dispatch Center. Results from the filtertype sampling system are used for environmental reporting. Both filter aerosol systems operate from the facility's emergency power system. Sampling locations are downstream of HEPA filtration systems. The 47-mm-diameter filters from both the CAM and passive systems are changed weekly and analyzed for gross alpha and gross beta activity. Based on our current understanding, the existing air monitoring systems are adequate to support the proposed MOX LA mission.

\section{7c. Waste Generation}

On-going activities at LLNL generate transuranic, low-level, mixed, hazardous, and non-hazardous wastes. Based upon current information on waste types expected to be generated by the MOX LA mission, existing facilities and procedures are adequate for storing and shipping wastes to approved facilities offsite as well as treating some forms of LLW, depending on a number of criteria (see 7a).

\section{Cost \& Schedule-Not applicable}

\section{Variance from Baseline Discussion-Not applicable}

\section{Response to Questionnaire}

Following are the LLNL answers to the MOX Lead Assembly Fabrication Questions for Characterization of Site Suitability. In each case, the question is plain type face, and the LLNL response is in bold typeface.

\section{A. MANAGEMENT/PERSONNEL}

1. Does this mission have site management commitment and does it not adversely affect other site activities? Please consider site status (operating vs. remedial action, external constraints, etc.). 
Site management has been appraised of this project and is interested in LLNL remaining a candidate site. Discussions are ongoing with top site management and with DOE management on project commitment. We do not believe that this activity would adversely affect other site activities.

2. Is/are the facility(s) proposed for the LA MOX fabrication mission uncommitted for other potential missions within the time frame of this project or free of any conflicts with other planned or ongoing missions? If not, identify other planned or potential missions and explain interfaces and potential conflicts.

The overall facility proposed for the LAMOX fabrication mission has several other projects that are ongoing and will continue throughout the LAMOX fabrication mission. However, we believe that LLNL's building 332 has available uncommitted space and supporting laboratories for the LAMOX fabrication mission. The current and planned projects for building 332 are: support to DOE-DP for nuclear weapons research, support for DOE-MD for plutonium disposition research, and support to DOE-EM for plutonium stabilization activities. These projects would use common storage vaults, analytical laboratories, MC\&A systems, etc.

3. Is the proposed lead assembly mission free of potential adverse affects on the future MOX production program if this site also was selected for the production mission?

LLNL is not a candidate for the production mission.

4. Will uncleared and/or foreign personnel be permitted to routinely access to the proposed LA MOX fabrication and assembly areas? What delays are expected from time of request to entrance? Will escorts be required?

Foreign personnel will be permitted routine access under escort from LLNL personnel. The average time for DOE approval from request to enter by foreign nationals visiting sensitive facilities is 30 to 45 days. If the personnel are repeat visitors no delays are expected, assuming the visit was identified initially as a continuing one.

5. Is the current program for protection and control of classified materials adequate to support the LA MOX mission and can classified and/or proprietary information be protected from uncleared foreign nationals? What measures are planned to protect such information?

The Building 332 RMA has an alternate entrance that would provide access to the LAMOX area visited by foreign nationals. This entrance avoids passage near almost all other sensitive areas of the facility. The lone exception can be mitigated easily and affordably. We anticipate that we would restrict access to foreign nationals to this alternate entrance and to the room where the LAMOX fabrication would be done. While in the LLNL 
Superblock all uncleared personnel will be under the escort of personnel with DOE clearances.

6. Are there provisions at the proposed site for protecting consortium proprietary information? What measures are planned to protect such information?

LLNL has facilities and performs experimental work that involve company proprietary information, such as the U-AVLIS project. This information is protected to the level agreed to with the outside company. LLNL has the infrastructure to support essentially any level of information protection.

7. Identify available exempt and non-exempt personnel with direct significant MOX fabrication experience (key names and total number).

The following plutonium handlers have fabricated MOX fuel assemblies: Terry Ludlow, William Kuhl, and Rich Burns. LLNL has the following professionals with limited MOX fabrication experience but no professional with direct significant fabrication experience: Martyn Adamson and Paul Densley.

It should be noted that LLNL leads the Immobilization Program for the DOE Fissile Materials Disposition Program. The Immobilization Program recently selected ceramic as the form for plutonium immobilization. The process operations for ceramic immobilization are essentially the same as that for MOX fuel. LLNL has been building up expertise, experience, equipment, and supporting analysis systems for the Immobilization Program that are directly applicable to MOX Fuel. Current schedules show the Immobilization Program activities at LLNL decreasing in the year 2000. This corresponds to when the MOX Fuel Lead Assembly Mission would need to start operations. Therefore, a staff of fissile material handlers and professionals trained in fuel fabrication technology (cold press and sintering) will be available to support a MOX Fuel Lead Assembly Mission.

8. Are there existing training organizations and facilities at the proposed site to adequately address required radiation worker training, respirator training and fitting, glove box training, criticality training, etc.? Describe existing capabilities and discuss the expansions needed in training resources needed to support specific LA MOX operations training.

LLNL has an existing training program and staff for radiation worker training, respirator training and fitting, glovebox training, criticality training, etc. To support a LA MOX mission additional staff would be required and a program set up for the additional training in quality control.

9. Are personnel security assurance (PSAP) and Fitness for Duty programs in place and are sufficient qualified personnel available to meet LA MOX mission requirements? Provide an estimate of any additional requirements. 
LLNL has a PSAP and Fitness for Duty program in place. A significant increase in PSAP personnel may require additional personnel for medical evaluations and program monitoring. It is estimated that 2-3 additional personnel will be required in this area.

10. Are sufficient personnel available with the necessary security clearances? If additional security clearance requirements are necessary, provide an estimate of the number of people and type clearance required.

Since LLNL is a matrix management system, a large number of personnel can be available with the necessary security clearances. However, we may need personnel with specific skills who do not have security clearances. For work in the Superblock, $\mathbf{Q}$ clearances are required.

\section{B. SITE/RESERVATION SPECIFIC}

1. Do the proposed LA MOX fabrication activities fall within existing site EIS and NEPA documentation? If not, what level of effort will be required to provide the required authorization/documentation?

LLNL is not doing MOX fabrication activities at this time, and some NEPA action would be required for LLNL to do this mission. The proposed plutonium amounts are within LLNL's existing EIS. The proposed uranium amounts are outside the existing EIS; however, since the uranium required for MOX is depleted, it is believe that a change to the LLNL EIS uranium limits will not be a problem. MOX LA Fabrication at LLNL will require additional site-specific NEPA analysis, probably at either an Environmental Assessment (EA) level, or by incorporating the project into a possible Supplement to the 1992 EIS for continued operations at LLNL. It must be noted that no decision has yet been made as to whether a supplement is needed. If a supplement is needed, the process would likely begin by early FY98 and would take approximately 18 months to complete. Alternatively, an EA for this effort would likely take 9-12 months, given the nature of the project.

2. Does the proposed site have existing external oversight agreements with local or state agencies and/or other stakeholder groups? Is it anticipated that these may adversely impact LA MOX siting and/or operations? Explain how these agreements might need to be amended to accommodate a LA MOX project.

There are no oversight agreements with local and state agencies for the Plutonium Facility operations. There are agreements between LLNL and state agencies on waste processing and storage. We do not think these agreements need to be amended to accommodate a LA MOX project.

3. Are existing fire department facilities appropriately located and adequately staffed and equipped for protection of the planned LA MOX facilities? If not, 
explain the physical and/or staffing changes needed to support the LA MOX production activity?

Yes

4. Are the existing medical support facilities and first aid stations appropriately located and adequately staffed and equipped for the planned LA MOX mission? If not, explain the physical and/or staffing changes needed to support the LA MOX production activity?

Yes

5. Are the existing site emergency response plans, staffing, and control center adequate for the planned LA MOX mission? If not, explain the physical and/or staffing changes needed to support the LA MOX production activity?

Yes

6. Are existing site-wide emergency planning and preparedness programs integrated with local, county and state agencies and adequately staffed and equipped for the planned LA MOX mission? If not, explain the physical and/or staffing changes needed to support the LA MOX production activity?

Yes

7. Does the proposed site have an active nuclear safety/criticality program implemented for the prevention of inadvertent nuclear safety/ criticality occurrences and is the program adequately staffed and equipped for the planned LA MOX mission? If not, explain the physical and/or staffing changes needed to support the LA MOX production activity?

Yes

8. If the proposed site is required to have safety, radiation protection, regulatory, quality assurance or other similar oversight committees for missions such as the proposed LA MOX fabrication mission, do such oversight bodies currently exist and have adequate staffing?

LLNL has safety teams that provide oversight for safety, radiation protection, regulatory, etc. For the LAMOX mission a separate team would be required for quality assurance. In addition, an increase in staffing would be required for the existing teams to support the increased activities from a LAMOX mission.

Describe responsibilities and programs.

Role - The four ES\&H Teams, organized through the Hazards Control Department, provide the key interface between the line organizations and the ES\&H support organizations. These Teams comprise safety and 
environmental specialists and technicians from Hazards Control and the Environmental Protection Departments. Each Team supports one or more directorates.

Responsibilities - The primary responsibilities of the ES\&H Team are to:

- Provide ES\&H technical support during normal operations and emergencies.

- Assist line organizations in identifying and analyzing health and safety hazards and environmental concerns in their operations.

- Advise line organizations of appropriate controls to eliminate or minimize the identified hazards and concerns.

- Advise line organizations of applicable ES\&H codes, standards, regulations, and DOE orders in a manner consistent with Laboratory policy, and assist line organizations in meeting mandatory requirements.

- Assist line organizations in environmental compliance actions; obtain environmental permits and variances as needed.

- Monitor the work environment for compliance with the Health and Safety Manual, LLNL Radiological Control Manual, Environmental Compliance Manual and Environmental Guidelines, applicable safety procedures, codes, standards, regulations and DOE Orders, and advise management on noncompliances.

- Take appropriate steps to ensure that any activity that presents an imminent, uncontrolled high-risk threat to human safety, health, or the environment is immediately stopped.

- Implement the ES\&H Teams Discipline Action Plans (DAPs) for each safety discipline.

- Provide guidance to line management in the development of safetyrelated procedures and documents (e.g., safety procedures, Radiological Work Permits, design reviews, etc.) and review such documents.

- Assist the Hazards Control Training Group in the development and teaching of ES\&H training courses.

- Assist in the analysis/investigation of accidents or incidents.

9. Are programs for operations security (OPSEC), technical surveillance countermeasures (TSCM), and foreign ownership, control or influence (FOCI) adequate to support the LA MOX activities? If facility upgrades or staffing enhancements are necessary, explain.

Yes

10. If the proposed plan requires intra-facility movement of SNM between processing steps, are qualified facilities, services and packagings available for 
intra-facility movement of the SNMs? If not, explain impact of providing these resources. If yes, briefly describe the available resources.

For plutonium transfer within Building 332 there are existing procedures, packaging, and transfer carts. For transfer of loaded fuel rods from Building 332 to Building 334, a packaging and transport system would be required.

11. Is the existing site safeguards and security plan (SSSP) adequate to address the needs of the proposed LA MOX mission? If not, explain the physical and/or staffing changes needed to support the LA MOX production activity?

Yes

\section{PROPOSED FACILITIES -}

1. Do the proposed facilities currently have sufficient qualified space for the main process operation to support LA MOX fabrication activities (an estimated 5000 square feet is required)? Describe adequacy of available space and/or anticipated efforts required to establish or modify space.

The space estimate on the original data request had an estimated $3000 \mathrm{ft}^{2}$. LLNL identified a room with $3200 \mathrm{ft}^{2}$. Addition space is available if $5000 \mathrm{ft}^{2}$ is required. Using a combination of Building 332 and Building 334, sufficient qualified space has been identified.

2. What is the current hazard category determination for the proposed facilities? Will LA MOX fabrication activities result in an increase of the hazard category? Discuss briefly.

The hazard category for the LLNL facilities are Category 2 nuclear facilities (non-reactor). This hazard category is sufficient for the LA MOX fabrication.

3. Are the proposed facilities being established/modified solely for this mission? Is there a continuing mission for these facilities independent of the LA MOX activity?

See $\mathrm{A} 2$ above. Specific rooms are being modified solely for this mission. For the overall facilities there is a continuing mission independent of the LA MOX activity.

4. What is the current operational status of the proposed facilities? Are they in active operational status or are they in legal compliance shutdown/inactive status under DOE-EM jurisdiction? Discuss briefly.

The facilities are in active operational status. They are under DOE-DP jurisdiction. 
5. What is the status of safety basis documentation (i.e. SARs, ISBs, BIOs with respect to DOE Standards and DOE Order 5480.23) for the proposed facility(ies)? Will the LA MOX fabrication activities fit within the scope of the existing safety documentation for the proposed facilities? If not discuss the extent of the changes needed in and resources required to modify safety basis documentation.

The SAR was updated last year to the new DOE standards. To our understanding the LA MOX activities are within the scope of the existing safety documentation.

6. Are any waivers or exceptions to applicable local, state or federal laws or DOE directives anticipated as a part of this mission? Discuss briefly.

No

7. Are there currently identified non-compliance's to DOE directives for any of the proposed facilities? If so, list the existing non-compliances and identify those which likely will need to be corrected prior approval of the proposed facility(ies) for the LA MOX mission. What are the estimated costs of making the required corrections?

\section{No}

8. Are the existing maintenance facilities, equipment, and support agreements adequate for planned LA MOX activities? List deficiencies, if any.

It is not clear what maintenance facilities are required. LLNL has extensive shop and maintenance facilities for maintaining overall plant operations.

9. Are the proposed facility areas currently contaminated? If so, what are the types and levels of contamination? Will decontamination be required prior to facility modifications/construction? Is there a current D\&D Plan for the proposed facility(s). If so, briefly describe the current plans and explain how they are impacted by this proposed use? What is the proposed incremental D\&D effort after LA MOX activities are completed?

The main room proposed for the LA MOX activities contains uncontaminated equipment. If additional space is required (see C1 above), then other rooms are available. These rooms, however, contain contaminated gloveboxes that would require removal and disposal. Outside of the gloveboxes there is no contamination. There is no current D\&D Plan for these facilities. Following the LA MOX activities, the equipment would either be transferred to other programs for use or would require D\&D.

10. Does/do the proposed facility(ies), or do other available on-site facilities, the capability for performing off-line process/fabrication technical support (i.e., dealing with powders having unusual characteristics, improving measurements and analytical techniques)? Briefly discuss these resources. 
The plutonium facility has supporting equipment for analytical chemistry, material characterization, powder characterization, etc. This supporting equipment will be available to support off-line activities.

11. Do provisions exist on site for handling and storage of TRU contaminated equipment items (pellet press dies, centerless grinding components, rod loading jigs, etc.) from the proposed LA MOX activities? If not, describe needed changes.

Provisions exist on site for disposal of TRU contaminated equipment. In use equipment is stored within the gloves or plutonium handling areas.

CA. Receiving and Vault Storage - SNM Cat 1; Haz Cat 2

1. Do vaults and/or vault-like rooms exist for the storage and processes associated with the LA MOX mission? If not, explain.

\section{Yes}

2. Is the hazard classification and allowed SNM quantities for the proposed facility(s) adequate to support the LA MOX mission? What are the allowed facility SNM quantities and isotopes and hazard classification (Please explain the bases in terms of compliance with DOE Order 5480.23).

The hazard classification is adequate to support the LA MOX mission (see C2). The current EIS limits plutonium to $700 \mathrm{~kg}$ and uranium to $300 \mathrm{~kg}$. Both weapons grade and fuel grade plutonium are allowed. The uranium limit would need to be increased to support the LA MOX mission.

3. Are proposed SNM storage areas operational and do they meet all applicable requirements for the storage of the planned quantities and types of SNM (PuO2 powders and MOX powders, pellets, rods and assemblies) for the LA MOX mission? If not, list deficiencies and/or proposed upgrades.

There are adequate operational storage vaults for feed powders and pellets. For rods and assemblies, Building 334 would be modified for use as an assembly and storage area.

4. Is the safety basis documentation for the storage vault current and are all hazards represented by the proposed LA MOX mission within the scope of the current authorization? If not, list deficiencies and judgment on the level of effort needed to revise the safety basis documentation.

For the building 332 storage vault the LA MOX mission is within the current authorization. For the storage of assemblies in Building 334, the current authorization basis will require revision to allow continuous material storage. The current Building 334 authorization basis only allows for nuclear material on a short term basis. 
5. Does the safety basis documentation currently cover the storage of Pu oxide? If not, explain how Pu oxide will be addressed.

Yes.

6. Is the size of the vault storage facility adequate to support the LA MOX mission and any other planned missions? If not, identify how the discrepancy will be addressed. Approximately what percent of the capacity of the vault storage facility will the LA MOX mission require during the MOX activities?

We believe that the current storage vaults will support the LA MOX mission. At any time, it is estimated that the LA MOX mission would require up to 20 percent of the existing vault storage capacity

7. Does an adequate shipping/receiving area exist for SST shipments? If not, list deficiencies and/or upgrades which will be needed.

Yes, the receiving area for feed material is currently able to accept this material in amounts of 10 DOT containers per shipment. Floor space for receival is limited. Vault space for storage of feed material and fuel pellets is sufficient. The receival space would be modified to permit a larger number of receivals at one time.

8. Does a nearby area exist where SSTs left overnight unattended can be parked and provided the appropriate security? If such an area exists, identify. If not, how could such an area be created?

SSTs can be left overnight within the LLNL Superblock, which provides appropriate security.

CB. Powder, Pellet and Rod Fabrication (PPRF) - SNM Cat 1 or 3; Haz Cat 2

1. What are the allowed relevant SNM quantities and isotopes for the proposed facility? Please explain the bases in terms of compliance with DOE Order 5480.23. List upgrades, if required.

\section{Same as CA2}

2. Will the proposed PPRF building structure meet containment requirements for handling significant quantities of dispersible $\mathrm{Pu}$ and $\mathrm{U}$ oxide powders. Include discussion of external events or natural phenomena hazards and formal seismic analyses which have been performed for the PPRF and the anticipated emissions from normal operations and a design basis accidents?

Building 332 routinely handles actinide oxide powders. The external events and natural hazards that have been analyzed are in the Building 332 SAR.

3. Does the proposed PPRF have a fire suppression system? Will it be sufficient/appropriate for LA MOX and powder operations? Explain any 
interaction with criticality controls and with the discharge of contaminated liquids from firefighting activities. Discuss any anticipated upgrades/enhancements.

Yes, there is a fire-suppression system and it is deemed sufficient. Contaminated liquids from firefighting activities are collected in Rasching ring filled drains and tanks.

4. What design features are present in the facility to prevent a criticality event? Does the facility have an acceptable criticality alarm system? Discuss any anticipated upgrades/enhancements.

A criticality event is prevented by control of process equipment geometry and control of masses allowed within workstations. The facility has an acceptable criticality alarm system.

5. Is the facility currently being used to process/handle $\mathrm{PuO} 2$ or similar nuclear materials? Explain limitations posed by ongoing activities with proposed LA MOX process line.

The facility is currently being used to process/handle $\mathrm{PuO}_{2}$ in amounts up to $4 \mathrm{~kg}$ plutonium per batch.

6. Does the proposed facility provide flexibility in the efficient layout of a LA MOX process equipment line?

An efficient layout of the LA MOX process line can be accomplished using Room 1013.

6.1 Explain limitations posed by existing glove boxes and/ or building features?

Existing gloveboxes would be removed from LA MOX processing rooms. Due to room height limitation, gloveboxes must be less than $11 \mathrm{ft}$.

6.2 Explain limitations in the modification of the existing glove boxes and/or building features to accommodate a LA MOX process line.

Existing gloveboxes would be removed from LA MOX processing rooms.

6.3 What is the maximum ceiling height available to allow the use of a gravity feed processing option?

Maximum ceiling height is $12-13$ feet.

7. Does the proposed facility currently have any operational prototypic process equipment (e.g. gloveboxes and process equipment, see Table in Appendix E) that might be used to fabricate qualified fuel for lead assemblies? Please describe and list the ROM cost value of these items. 
The facility has equipment that is being used to make ceramic waste forms but this equipment is not considered prototypical of equipment that would be used to fabricate qualified fuel for lead assemblies.

8. What are the proposed cold startup and hot startup plans following facility/equipment readiness? Describe the proposed approach for establishing a LA MOX processing baseline.

As this project is several years away and DOE is only looking at candidate facilities, this question seems very premature. Proposed cold startup and hot startup plans would be formulated with the DOE-MD program and the selected MOX fuel vendor (or consortium).

9. What are the proposed fuel batch sizes for processing (i.e., blending, pellet fabrication)? Briefly describe the planned batch processing strategies including the sequencing of batches, anticipated holdups quantities (in-line and analytical) and interim storage requirements.

LLNL has not been involved with designing a MOX fabrication facility. We do not have a proposed batch size or processing strategy. As a facility that can handle Category 1 quantities of plutonium, we can batch plutonium oxide quantities up to limits imposed by critically safe configurations and masses.

CC. Ventilation System:

1. Does the proposed building have an operating HEPA filtered, zone controlled ventilation system approved for handling $\mathrm{Pu}$ oxide powders? If yes, would upgrades be anticipated for the LA MOX activities? If no, explain anticipated installation or upgrades to provide an adequate system?

Yes, and no upgrades are anticipated at this time.

2. What provisions are or will be provided to contain contamination at its source of generation?

Gloveboxes with be equipped with HEPA filters to contain contamination to process gloveboxes. The facility is operated with a zoned ventilation system. The gloveboxes (zone 1) are maintained at a negative pressure compared to the rooms (zone 2), which are maintained at a negative pressure compared to the halls (zone 3). Exhaust gas from all zones is double HEPA filtered prior to exhaust from the facility.

3. Explain the relationship of the glove box off-gas system to the room and to building ventilation systems. Provide a brief description of the ventilation zones.

See CC2 above. 
4. Does the discharge stack have sufficient height and appropriate stack monitoring features sufficient to support the LA MOX activities? If not, explain deficiencies and/or proposed upgrades.

Yes

5. Does the facility have inert gas and/or controlled humidity ventilation capability for the powder blending gloveboxes? Describe the proposed approach for glovebox environment control.

The facility has both nitrogen or argon gases from liquid storage tanks.

6. Have ventilation system components been identified by safety function and qualified to appropriate enhanced criteria based on the safety function? List.

Yes. Details of ventilation system components are in the Building 332 SAR, Chapter 4.

CD. Normal and Emergency Electrical Power:

1. Are the capacity, reliability, and availability of the existing normal electrical power distribution systems to and within the facility adequate for planned LA MOX activities? Describe system and component qualifications.

Yes. See Section 3a, Utilities, Electrical Power.

2. Does the proposed facility have an existing emergency/backup power system to accommodate the needs of the LA MOX mission? This should include power for safety-related equipment function (e.g., HVAC, monitoring, etc.) and cooling systems necessary for the safe shutdown of the sintering furnace(s) and other equipment. Describe backup or emergency power system capacities and levels of code qualification.

Yes, it has an existing emergency/backup power system. See Section 3a, Emergency Diesel Generator, Uninterruptible Power Supplies.

\section{CE. SAFEGUARDS AND SECURITY}

1. Are the existing physical protection systems/components (e.g. barriers, detection and assessment, access control, communications) adequate for the LA MOX mission? If not, list deficiencies and/or upgrades needed.

Yes, pending a favorable vulnerability analysis (VA), which is anticipated with perhaps some mitigations.

2. Will the S\&S support for the proposed facilities for the LA MOX mission be independent of other site operations (or will it rely on site-wide capabilities such as barriers, central/secondary alarm stations, communications, access 
control systems, other protective forces, special response forces)? If other site assets are used, identify.

The S\&S support will largely not be independent of other operations. If the VA reveals mitigations are necessary to accommodate LA MOX, then S\&S support would be added as either a dedicated effort or an enlargement of existing operations to compensate for LA MOX conditions.

3. Is the existing classified automated information system adequate to support the LA MOX mission?

Yes

4. Are any of the proposed facilities to be used for the LA MOX mission under IAEA safeguards now or will they be during the time period of this mission? If so, provide details.

No

5. Are there any materials, information and/or activities at the facilities to be used for the LA MOX mission that would need to be protected from IAEA inspectors and/or foreign visitors? Explain.

Yes. There will be ongoing nuclear weapons activities in other increments and rooms in the Plutonium Facility. IAEA inspectors and or foreign visitors would be under escort and have access limited to Increments 3 and the room required for the LA MOX mission.

\section{CF. Compliance:}

1. Will the current facility/site environmental permits meet the requirements of the proposed LA MOX activities? If not, what is the anticipated level of effort required to obtain revised permits?

No; see Section 7.

2. Does the facility have adequate personnel radiological monitoring equipment (including survey, hand and foot counters and continuous air monitors for $\mathrm{Pu}$ and $\mathrm{U}$ ) available for the LA MOX activity. If not, what supplemental equipment is anticipated?

\section{Yes}

3. Describe how ALARA considerations will be implemented in the facility to accommodate the LA MOX activities that may include significant americium content.

Equipment being designed and installed for the LA MOX activities would have to meet Code of Federal Regulation requirements for radiation 
exposures. Since this prototype equipment is the same as that planned for the MOX plant, it should be designed with ALARA considerations in mind.

CG. Other Features Required:

1. Does the facility have adequate personnel decontamination and change room facilities for both male and female? If not, how will these capabilities be provided?

The facility currently has two male and two female change rooms. Only one set is currently being used. The LA MOX mission would require the activation of the other set of change rooms.

2. How will contaminated liquids from decontamination operations ( personnel decontamination, safety showers, etc.) be handled? Explain the relationship to existing waste water treatment facilities.

Liquids from safety showers are captured in isolation tanks and sampled for potential contamination prior to release. Contaminated liquids from personnel decontamination are collected in localized tanks and then treated by batch processing.

3. Does the facility have adequate offices for the required operating staff convenient to the facility(s)? Approximate number available.

No. Facilities would need to be modified or new facilities installed to provide additional offices.

D. BUNDLE ASSEMBLY - SNM Cat 1; Haz Cat 2

1. Is the proposed bundle assembly area located in the PPRF processing facility? If not explain the relationship between the two facilities and answer questions $2-4$ below.

The proposed bundle assembly area is located in a separate facility (Building 334). The PPRF would be in Building 332. Both Building 332 and Building 334 are in the LLNL Superblock. These two building are within a few hundred feet of each other.

2. What is the current hazard classification of the proposed facility? What are the allowed SNM quantities and isotopes? (Please explain the bases in terms of compliance with DOE Order 5480.23).

The current hazard classification is Nuclear-Category 3.

Allowed SNM is:

$12 \mathrm{~kg}$ of $\mathbf{P u}^{239}$ 
$12 \mathrm{~kg}$ of $\mathrm{U}^{235}$

Although not considered SNM, there is an $80 \mathrm{~kg}$ limit on depleted Uranium.

3. Is the safety basis documentation for the assembly area current and are all hazards addressed? If not, discuss anticipated approach.

For the current operation, yes.

4. Does the safety basis documentation currently cover the handling of MOX fuel? If not, discuss anticipated approach.

No. It covers encapsulated nuclear weapon components. The Building 334 SAR would be revised to include handling and storage of MOX fuel.

5. Briefly describe the vertical space proposed that has a minimum clearance of 20 feet ( from hook of a 1 ton lifting device) for the required vertical inspection of fuel bundles.

The high bay is $40 \mathrm{ft} \times \mathbf{5 0} \mathrm{ft}$ with a ceiling height varying from 28 to 30 feet. A 5-ton bridge crane traverses the entire bay, with a trolley that travels end to end within about two feet of the wall. The crane hook is mounted so that the vertical clearance of the hook above the floor is 20 feet.

\section{E. BUNDLE STORAGE AND SHIPPING-SNM Cat 1 ; Haz Cat 2}

1. Do adequate facilities exist for the vertical storage and rotation to the horizontal for shipping of the bundles? If not, discuss anticipated approach.

Facilities is an ambiguous word. The facility (B334) exists. The facilities (capability) to store bundles in a vertical position do not exist. The facility (capability) to rotate from the vertical to the horizontal does exist in the bridge crane but should be improved upon.

The discussed approach to vertical storage is to secure two DOE-approved rack systems to the wall that would hold four bundles each. For the transition from the vertical to the horizontal, some sort of guide system could be installed to reduce the degrees of freedom on the bundles as they are rotated.

2. Is the proposed bundle storage area located in the proposed receiving storage vault? If not explain relationship and answer questions 3 - 5 below.

No, they are in different buildings.

3. What is current hazard classification of proposed facility? What are the allowed SNM quantities and isotopes? Will these be impacted by the proposed LA MOX activities? (Please explain the bases in terms of compliance with DOE Order 5480.23). 
The current hazard classification is Nuclear-Category 3.

Allowed SNM is:

$12 \mathrm{~kg}$ of $\mathrm{Pu}^{239}$

$12 \mathrm{~kg}$ of $\mathrm{U}^{235}$

Although not considered SNM, there is an $80 \mathrm{~kg}$ limit on depleted Uranium.

As I understand the activity, neither the $\mathrm{Pu}$ or the $\mathrm{U}$ limits are a problem. However, the depleted-uranium limit may be an issue. Since the depleteduranium limit is below the threshold for Category 2 facilities, it appears that an addendum to the B334 SAR raising that limit would suffice.

4. Is the safety basis documentation for the bundle storage facility current and are all bundle storage and shipping hazards addressed? If not, discuss anticipated issues.

The safety basis documentation is current. The bundle storage hazards have not been addressed as they are not part of the current operations. The anticipated issues are addressed in E.1 and E.3 above.

5. Does the existing safety basis documentation cover the handling of MOX fuel? If not explain how the MOX-related issues will be addressed.

The existing documentation does not cover MOX fuel. Documentation will be based upon the USQD and any required SAR addenda. The hardware for the vertical storage would be installed by Plant Engineering crafts, according to current LLNL seismic standards. If a guide mechanism for the rotation of bundles from vertical to horizontal is of value, the Mechanical Engineering Department would design, review, test, fabricate, and install the fixture.

6. Briefly describe how completed bundles will be stored in proposed facility (i.e. vertical hanging storage array with strongback for horizontal packaging and shipping).

This will be determined by the performing vendor.

\section{F. WASTE}

1. Does the proposed site currently have a TRU waste generator certification plan and the NDT equipment to separate LLW from TRU waste and to certify TRU waste for disposal in WIPP? If not, explain deficiencies. Also, discuss plans for RCRA waste handling, if required.

LLNL has a TRU waste generator certification plan. A high-sensitivity neutron instrument (HSNI), which has been qualified by successful analysis of NDA PDP sources, is used routinely to separate LLW and TRUW. A TRU 
waste QAP for characterization acceptable to WIPP is in place. Components of the plan included (1) a formalized collection of generator knowledge, (2) real-time radiography, (3) radionuclide analysis by SGS, (4) headspace gas analysis, and (5) gas-generation tests. Components of the characterization plan are at various stages of readiness and all evolve and improve with time. LLNL Superblock workstation procedures call for generation only of "Dry Solid" waste (see, LLNL TRUCON codes). Toxic mixed waste is acceptable to WIPP (no corrosive, liquid, or reactive components permitted, but RCRA metal oxides in a dry form allowed).

2. Do you anticipate the treatment (i.e., immobilization for respirable fines) of any of the TRU waste generated? If so, does the proposed site have the required facilities? If not, explain deficiencies.

Procedures with systematically reviewed OSPs are in place for thermal treatment of radionuclide waste, for neutralization and solidification (Aquaset) of aqueous waste, for solidification of organic waste liquids (e.g., oil) with Petroset, and for immobilization of metallurgical fines into epoxy resin. Respirable fines are solidified with liquids only if they constitute a waste component, but not if they merely contaminate other waste components. The necessary facilities are located in the RMA in Room 1378.

3. Will the quantities of TRU waste expected to be generated in this LA MOX project have any impact on the TRU waste storage situation at the site, including existing agreements with the state and local governments? Explain this situation for the proposed site.

In our experience, research and development projects of this size produce relatively little waste (in terms of curie content). Of the $50-65 \mathrm{~kg}$ of plutonium waste expected from MOX fuel rod production (see Proposal, Table 1-3, p. 6), only a fraction-perhaps, $1-2 \mathrm{~kg}$-will be waste as defined by LLNL. This will increase TRU waste production by less than $25 \%$ and can be accommodated. Currently, LLNL is arranging to increase the storage limits on the 612 waste yard by 10x. Also, new storage facilities in Buildings 280 and 696 will be available during the coming year, and shipments to WIPP are scheduled to begin in October 1999. Most of what is termed "waste" will be scrap with some residual value. LLNL returns or stores such scrap, and will want to return scrap to producers. LLNL has no desire to increase the amount of material in storage vaults. Reprocessing of scrap is an issue that should be addressed at an early stage if MOX fuel production is to viable.

4. Does the proposed site charge the generators for waste management? If so, what are the ROM costs for waste management for the projected quantities?

LLNL handles waste management as a service to programs, so costs are indirect. The facility bears some responsibility for storing filled TRU waste drums until they are accepted for storage Hazardous Waste Management, and living up to WIPP WAC for certification and the WIPP QAPP for 
characterization. There are currently no direct charges to programs, although Work for Others contracts pay a small waste management burden.

5. Does the proposed site have the necessary facilities (either on or off site) and/or plans for the interim storage and disposal of the projected quantities of solid LLW? Explain the situation for the proposed site.

LLW ( $<100 \mathrm{nCi} / \mathrm{g}$ ) is shipped to the Nevada Test Site for disposal. LLNL has a long-term agreement with the Test Site and takes the necessary steps to send only certified LLW. Certified LLW would result from this work.

6. Does the proposed site have facilities for volume reduction of solid radioactive waste? If so, briefly describe available facilities and their capabilities. If not, discuss the plan for overcoming this deficiency.

TRU waste parcels are collapsed (air removed) during the bagout process. LLW (lab trash) is routinely compacted. Currently, in-drum compaction of all LLW is under consideration and will likely be implemented during FY98.

7. Does the proposed site have operating facilities for the collection and disposition (including sludges), of contaminated liquids projected to be generated from decontamination of facilities, equipment and personnel (i.e., shower and mop water)? If not, discuss the plan for overcoming these deficiencies.

Shower and sink water goes to a carefully monitored retention tank that has operated without incident for some years. Water from spill cleanup and decontamination including sludges would be sent to "Plutonium Recovery" for treatment, and eventually solidified with Aquaset. These facilities and capabilities are in operation at the present time.

8. Are the anticipated liquid, solid, and gaseous waste streams, both radioactive and non-radioactive, consistent with permitted activities at the proposed site? If not, discuss the measures planned to achieve compliance.

Based on the HWM Waste Acceptance Criteria (UCRL-MA-115877, Rev. 1; Aug., 1997; see, http://www/linl.gov/linl_only/es_and_h/wac_rev1/wac_contents.html) none of this project's wastes are of particular concern.

9. What are the anticipated waste minimization plans for this LA MOX facility?

Design review will have as one important focus waste-minimization measures. Minimization and disposal of scrap will also be addressed.

10. Describe the waste types and quantities expected to be generated during facility(ies) modifications. 
Rooms 1005 and 1009, and other proposed areas in the RMA, are clean and free of radionuclide activity. Construction trash could be disposed of to landfill after appropriate monitoring. Similarly, B334 is uncontaminated. The small amount of construction needed in analytical labs and supporting facilities is typical of the evolving nature of these workstations. No unusual wastes are expected.

\section{G. ANALYTICAL}

1. Does the proposed site currently have operational analytical services capability for the list of analyses required for the LA MOX mission that was provided in Table 4.1? Please describe and provide the ROM costs and turnaround times for these analytical services. Identify deficiencies for the required analyses and turn-a-round times.

LLNL has some of the analytical capabilities but not all. LLNL would need to install the following additional analytical instruments in addition to those installed as part of the MOX Fuel Line: ICP Mass Spectrometer, Thermal Ion Mass Spectrometer, and Ion Chromotography. These instruments would be installed in the current analytical laboratories located in Rooms 1313, 1321, and 1329. LLNL is currently installing a BET system for powder surface area determination and a laser scattering particle size analyzer in support of the Immobilization Program.

Analytical costs are directly related to the time an analytical chemist spends on a sample. This time is dependent on the type of analysis need. Currently, LLNL has only one analytical chemist working in the Plutonium Facility. Sample analysis turn-around time is usually a few days to two weeks. However, with a MOX Fuel Lead Assembly Mission, LLNL would increase the analytical chemistry staffing in the Plutonium Facility. The cost per analytical chemist is approximately $\$ 200 \mathrm{~K}$ per year.

2. Does the analytical laboratory have the resources and capability to establish and maintain calibration and certification? If not, what are the plans for overcoming this deficiency?

Analytical instruments are calibrated per vendor specifications. LLNL participates in a DOE-wide program to certify analytical techniques to measure plutonium oxides. However, it is anticipated that a more in-depth calibration and certification program will be required for MOX Fuel. As part of the MOX Fuel QA Plan, a calibration and certification program would be implemented. LLNL will over the next year be putting together a calibration and certification program for ceramic immobilization to support the disposition of plutonium ceramic in the High Level Waste Repository (HLWR).

3. Does the proposed site currently have MOX fuel sampling/quality assurance plans? Briefly describe these plans. 
LLNL does not currently have MOX fuel sampling/quality assurance plans.

\section{H. PHYSICAL SECURITY}

1. Is an adequately equipped and trained Protective Force available on-site and can it be reinforced within a required response time to protect the SNM for the proposed site? Describe.

Yes. Details in classified SSSP.

2. Is an $S \& S$ performance assurance program in place and adequate to support the LA MOX mission (e.g. S\&S maintenance, testing, records management)? Describe.

Yes.

3. Has consideration been given to changes in the site-specific threats due to the LA MOX mission? Explain.

Yes, but only informally, and the belief is that minimal impact would have to be addressed for LAMOX. A detailed understanding of material types, quantities, locations, etc., has to be analyzed more formally in a VA to satisfy LLNL commitments to DOE that the SSSP is revised appropriately when conditions or assumptions change.

4. Has a preliminary vulnerability analysis and risk assessment been done for the LA MOX activities? If yes, briefly describe any key issues.

No. Again, descriptions of the scope of work given to a S\&S professional assigned to the facility revealed that minimal impact would result from LAMOX, but that has to be qualified by a desktop and perhaps a full VA.

\section{SNM MATERIALS CONTROL AND ACCOUNTABILITY}

1. Are the existing materials, control and accountability (MC\&A) systems/components (e.g. nuclear measurements/assays, materials accountability, MC\&A computer system) adequate for the LA MOX mission? If not, identify required upgrades.

The nuclear material measurement equipment on site is adequate for measuring the raw materials input to the LA MOX project; i.e. Plutonium oxide and low-enriched Uranium (LEU) oxide. However, standards representative of the LEU oxide are required to calibrate instruments for good accountability measurements. LLNL has standards adequate for measuring the Plutonium oxide. LLNL does not have measurement equipment adequate for measuring the finished fuel rods. The MOX pellets could be measured before loading in fuel rods, but again, standards representative of the pellets would be needed to calibrate instruments for good accountability measurements. If measurements of the finished product 
are required, LLNL will have to procure either an Active Well Coincidence Counter (AWCC) that can be figured to count fuel rods piecewise or a rod scanner. In either case, LLNL will have to obtain/develop representative standards.

All other aspects of the MC\&A system are adequate, although depending on the scale of the project, some computer system upgrades for the MC\&A database system may be required.

\section{J. SHIPPING AND RECEIVING}

1. Are the LA MOX fuel fabrication facility(s) transportation systems and shipping/receiving areas for off-site receipt/shipment of SNM adequate for the anticipated quantities of SNM? If not, what modifications are needed?

Onsite containers to carry loaded fuel rods between B332 and B334 would need to be fabricated and approved.

Various handling devices for the loading of the fuel assembly onto the SST would need to be purchased. The type of loading device required would be determined by the weight and shape of the assembly and the modification, if any, required to the current SST Trailer.

\section{Cost and Schedule Risk-Not applicable}

\section{Conclusions}

LLNL has essentially all the support functions required to support a MOX Fuel Lead Assembly Mission at LLNL. These support functions include: security systems, qualified utility systems, fire-protection systems, analytical laboratories, waste-handling systems, up-to-date ES\&H documentation, and DOE-compliant MC\&A. The LLNL team has identified the following regulatory and permitting efforts that would be required for LLNL to accomplish a MOX Fuel Lead Assembly Mission: update NEPA documentation for Building 332 to cover MOX fuel fabrication; increase uranium limits for Building 332; and change the Building 334 Safety Analysis Report (SAR) for bundle assembly and storage. The LLNL departments that deal with the regulatory agencies do not feel that these changes are very significant. Areas where new functions are required or additional capacity is required include: MOX Fuel Fabrication Line, Bundle Assembly and Storage Facility, MOX fabrication expertise, additional calorimeters for MC\&A, and additional analytical equipment to support specific-impurity analysis. However, these areas are required by essentially all potential DOE facilities being examined, and the areas where LLNL plans to place the new equipment can be quickly reconfigured since the existing systems are noncontaminated.

Although this plan did not include a cost analysis, LLNL should have a very low cost compared to sites where significant upgrades are required. Both 
LLNL management and DOE Oakland management are supportive of LLNL as a candidate site for this mission. Due to time and funding limitations, this plan does not contain all the detailed information that may be desired. Provided adequate funding and time, LLNL will provide additional detail if requested by DOE. 
THIS PAGE INTENTIONALLY LEFT BLANK. 


\section{APPENDIX}

\section{LAYOUTS}


THIS PAGE INTENTIONALLY LEFT BLANK. 

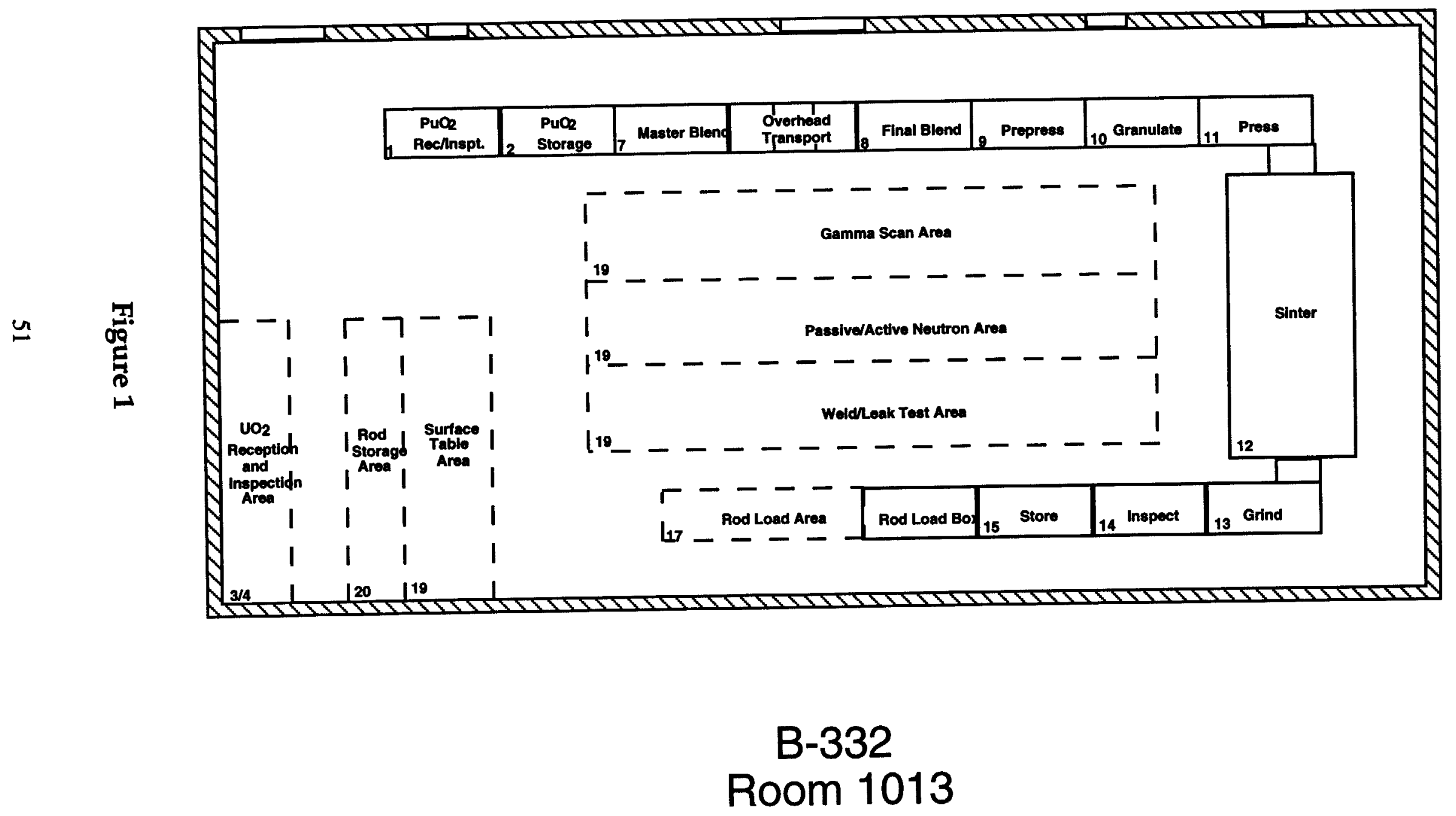


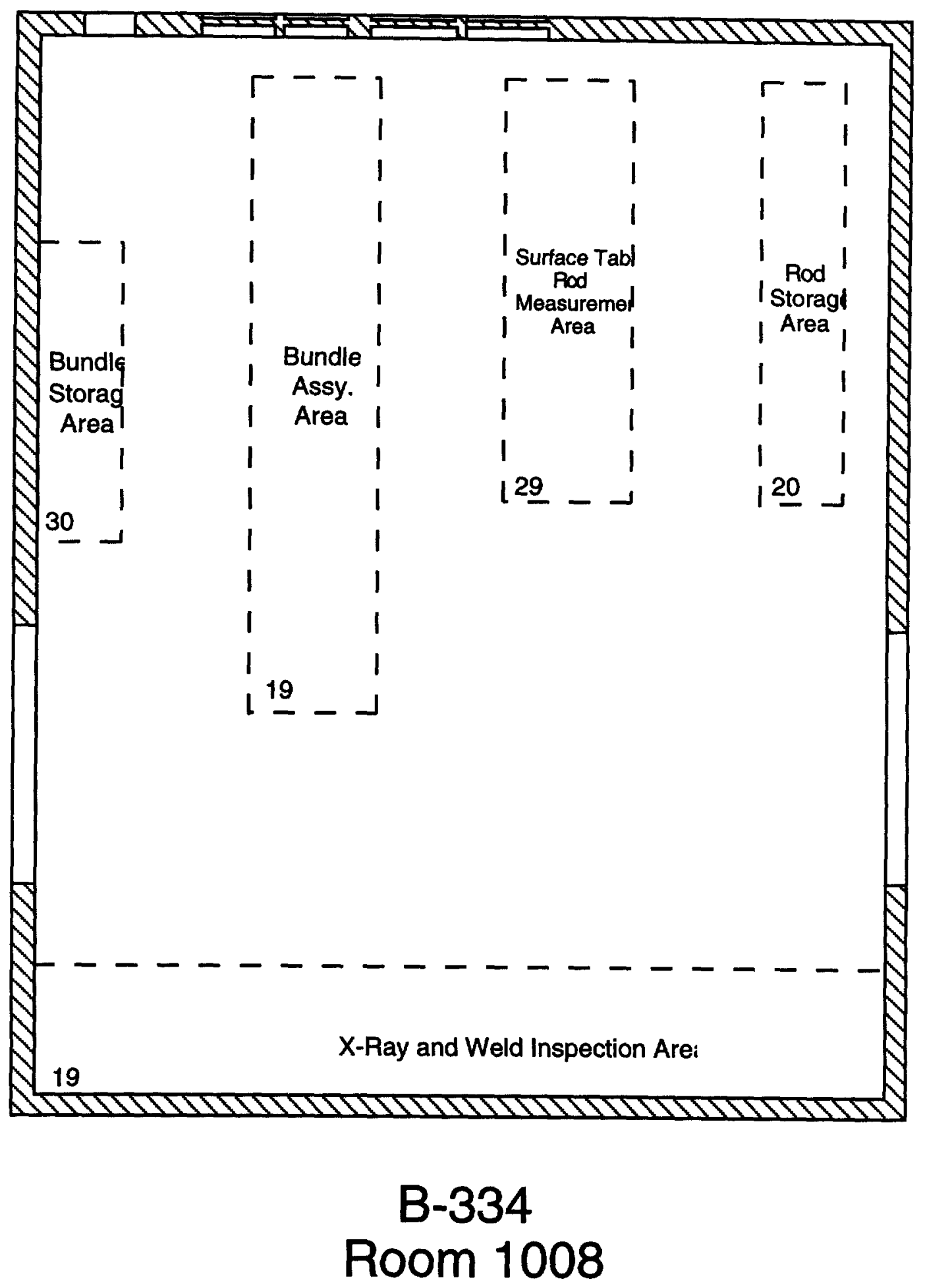

Figure 2 


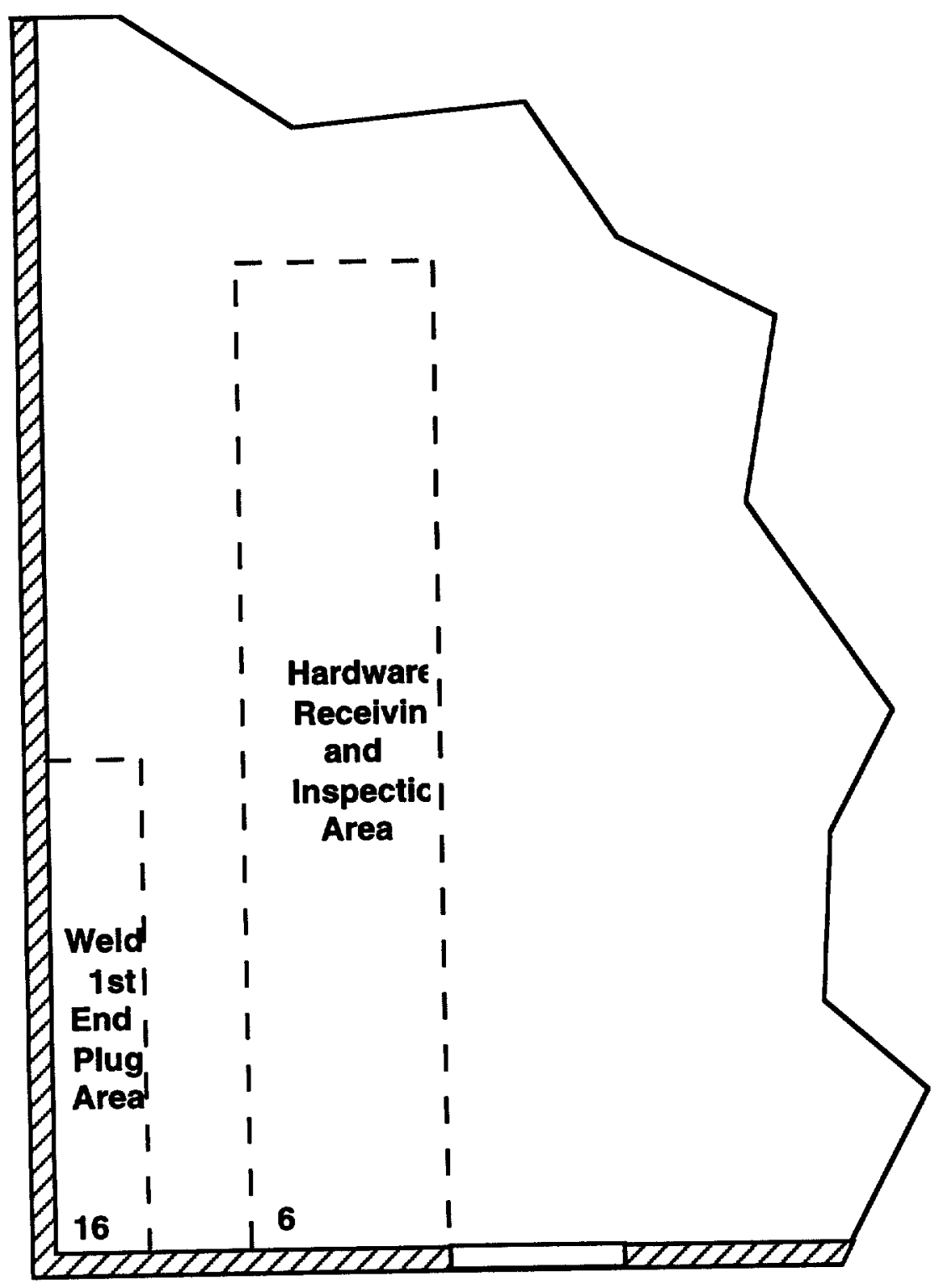

\section{B-335 \\ Room 111}

Figure 3 
THIS PAGE INTENTIONALLY LEFT BLANK. 


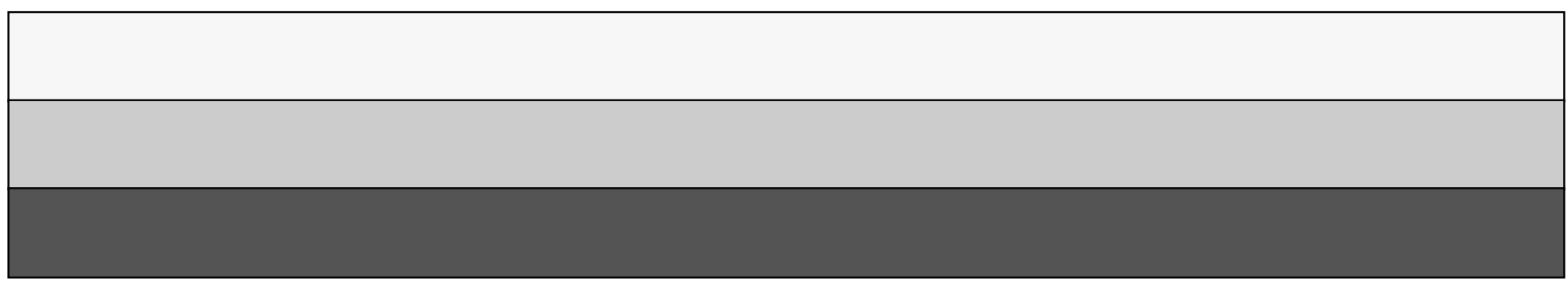

